\title{
Preparation, dielectric and a.c. conductivity studies on chemically treated sisal powder filled polyvinyl alcohol biocomposites
}

\author{
Archana Nigrawal* and Navin Chand
}

Advanced Materials and Processes Research Institute, Bhopal (CSIR) (formerly RRL Bhopal), Habibganj Naka,Bhopal -462064, INDIA

"Corresponding Author: e-mail: archananigrawal@yahoo.co.in Tel +91-0755--2417511

\begin{abstract}
In this paper, development and electrical characterization of sisal powder filled polyvinyl alcohol (PVA) composites is reported. Dielectric measurements were conducted on these composites on a LCR meter in the temperature range from 30 to 150 ${ }^{\circ} \mathrm{C}$ and in the frequency range $1 \mathrm{kHz}-10 \mathrm{kHz}$. The effects of temperature and frequency variation on dielectric constant $\left(\varepsilon^{\prime}\right)$, dielectric dissipation factor ( $\tan \delta$ ) and on a. c. conductivity ( $\sigma a . c$.$) were determined. On increasing the filler content, dielectric$ constant increased, it was mainly due to motion of the dipolar groups of the interfacial polarization occurring in the composites. The conductivity increased with rise in temperature.
\end{abstract}

Keywords: PVA, Electrical Properties, Dielectric Properties, Electrical Conductivity

\section{Introduction}

In order to keep the environment free from pollution, the use of biodegradable and environmental friendly polymer is important and hence it has attracted the interest in natural polymer. Natural polymers like sisal,jute, kenaf, pineapple, flax, wood etc are biodegradable and can easily decomposable in the environment. Demand for biodegradable and biocompatible materials has rapidly increased, specially in the packaging sector where it is highly encouraged by environmental polices. PVA is among the most promising biodegradable polymers currently available on the market. PVA films are increasingly used as solid polymer electrolytes when they are doped with metal additives in solid state electro chromic displays (Mahmoud et al., 2008; Ramakrishna et al., 2009; Scarponi and Pizzinelli, 2009). The wider applications of PVA arise because of its chemical and physical properties. Different additives are usually added to PVA polymer in order to modify and improve its properties and impart a high level of durability against environments. The electrical properties of natural fiber reinforced polymer composites are very important due to their unique property as inorganic insulators. Sisal fiber is a promising reinforcement for use in composites due to its low cost, low density, high specific strength and modulus, no health risk, easy availability in some countries and renews ability. In recent years, there has been an increasing interest in finding new applications for sisal-fibre-reinforced composites that are traditionally used for making ropes, mats, carpets, fancy articles and others (Andrej et al., 2009)).

Idicula et al. (2006) studied the thermo-physical properties of banana/sisal hybrid fibre reinforced polyester composites. They found that hybridization with glass fibre increased the heat transport ability of the composite. In a paper thermal properties of the hemp fibre composites were improved by hybridization with glass fibres (Nayak and Mohanty, 2010). Thermal properties of sisal/glass hybrid composites displayed that the addition of glass fibre improved thermal properties of sisal composite (Samal et al., 2009)..In another study, the thermal diffusivity and conductivity of sisal and glass fibre reinforced polyethylene composites was reported (Kalaprasad et al., 2000). Electrical properties of natural fiber reinforced polymer composites indicates their suitability as dielectric materials in microchips, part of transformers, suspension insulators, bushings, studs, sleeves and switch boards. These materials can also be easily employed for multi-function applications such as the hollow cellular structure of plant fibers proved effective in providing insulation against heat and noise (Andrej et al., 2009; Idicula et al., 2006). The advantages of 
PVA such as high mechanical strength and water-soluble have played as main role for this selection as compared to other polymer matrices. PVA is one of this new generation of polymeric materials.

The study of dielectric constant and dielectric loss as a function of temperature and frequency is one of the most convenient and sensitive methods of studying polymeric structure. Electric properties of pineapple reinforced polyethylene composites have been studied by Jayamol et. al. (1997). They observed that the increase in the dielectric constant of composite with fiber loading was due to increased orientation and interfacial polarization.

Yang et al. (1996) studied the relationship of surface modification and tensile properties of sisal fibers. Their modification methods included alkali treatment, $\mathrm{H}_{2} \mathrm{SO}_{4}$ treatment, combined $\mathrm{H}_{2} \mathrm{SO}_{4}$, and alkali-thermal treatment. They found that thermal treatment was the most desirable method in terms of strength and modulus properties. Recently mechanical and thermal properties of sisal fibre powder filled PVA composites were analysed and reported (Yang et al., 1996). Sisal fiber reinforced polypropylene composites having different weight percent sisal fiber with and without Maleic anhydride grafted polypropylene (MAgPP) have been developed by melt mixing method and dielectric properties such as $\varepsilon^{\prime}, \tan \delta$, and a.c. conductivity of these composites with and without MAgPP have been determined (Chand et al., 2008). Recently, mechanical properties of the biocomposite films having different wt $\%$ of treated sisal fibre powder with and without nano alumina powder were reported (Nigrawal et al., 20011). In this work, sisal fibre filled PVA composites were developed and characterized for their dielectric and a.c. conductivity behaviour.

\section{Materials and Methods}

Sisal fibre was obtained from Sieoni, India and powdered to - $355 \mu \mathrm{m}$ size by cutting in a cutting machine. Sodium hydroxide $(\mathrm{NaOH})$ obtained from Merck Ltd. Mumbai India. PVA(BIO)-from Sigma Aldrich Hydrolysed (98-99\%) was used in this study ,which had an average mol.wt- 146000 and MP. $200^{\circ} \mathrm{C}$.

\subsection{Chemical treatment of sisal powder}

Sisal fibre powder of size $-355 \mu \mathrm{m}$ was soaked in a $5 \% \mathrm{NaOH}$ solution for $70 \mathrm{hrs}$ at room temperature. After treatment the sisal fibre powder were washed by distilled water five times and finally rinsed with cloth and then dried in an oven at $100^{\circ} \mathrm{C}$ for $2 \mathrm{hrs}$.

\subsection{Composite preparation}

Treated and untreated sisal fibre powder/PVA composites were prepared having $0,1,3$ and $5 \%$ sisal fibre powder, by solution casting method. PVA solution was prepared by heating of the desired quantity PVA solution in distilled water at $80^{\circ} \mathrm{C}$ for $2 \mathrm{hrs}$. After this 1,3 and 5 wt $\%$ treated and untreated sisal fibre powders were added to separately solution and stirred. In a separate PVA solution desired quantities of heated sisal fibre powder were added and film were casted. Stirred gel was poured on a petri dish to make film.

\subsection{Dielectric and a.c. conductivity measurements}

Capacitance (C) and $\tan \delta$ values of the composites were measured by using a Hewlett - Packard, LCR Meter, model 4274 A, in the temperature range 30 to $150{ }^{\circ} \mathrm{C}$ and frequency range from 1 to $10 \mathrm{kHz}$. Heating rate was kept constant at $\pm 1{ }^{\circ} \mathrm{C} / \mathrm{min}$. Dielectric constant $\left(\varepsilon^{\prime}\right)$ was calculated by using the following relation

$$
\varepsilon^{\prime}=\mathrm{C} / \mathrm{C}_{\mathrm{o}},
$$

where $\mathrm{C}$ and $\mathrm{C}_{\mathrm{o}}$ are the capacitance values with and without sample, respectively;

$$
\mathrm{C}_{\mathrm{o}} \text { is given by }[(0.08854 \mathrm{~A}) / \mathrm{d}] \mathrm{pF} \text {, }
$$

where $\mathrm{A}\left(\mathrm{cm}^{2}\right)$ is the area of the electrodes and $\mathrm{d}(\mathrm{cm})$ is the spacing between the electrodes. $\tan \delta$ is the dissipation factor and is defined as follows

$$
\tan \delta=\varepsilon ' / \varepsilon,
$$

where $\varepsilon "$ is the dielectric loss.

a.c. conductivity of the sisal powder filled PVA composites was calculated by using the following formula

$$
\sigma_{\text {a.c. }}=\varepsilon_{0} \omega \varepsilon ' \tan \delta \approx \varepsilon_{0} \varepsilon^{\prime \prime} \omega
$$

where $\tan \delta$ is the dissipation factor and $\omega$ is the angular frequency, which is equal to

$2 \pi \mathrm{f}$ (where $\mathrm{f}$ is the frequency). $\varepsilon_{0}$ is the permittivity of free space.

Relaxation time of sisal fibre filled PVA composites has been calculated by using the following formula reported earlier (Chand et al., 2008). 


$$
\tau=1 / \omega\left[\sqrt{ }\left(\left(\varepsilon_{0}-\varepsilon_{\infty}\right) /\left(\varepsilon^{\prime}-\varepsilon_{\infty}\right)\right)-1\right]
$$

where $\tau$ is the relaxation time, $\varepsilon_{0}$ and $\varepsilon_{\infty}$ are the dielectric constant values at lowest and maximum frequency respectively.

\section{Results and Discussion}

Fig. 1 depicts the variation of dielectric constant $\left(\varepsilon^{\prime}\right)$ with temperature for Pure PVA . It is observed that $\varepsilon$ ' increased with increasing temperature and decreased with increasing frequency. At lower temperature, $\varepsilon$ ' values at different frequencies merged.

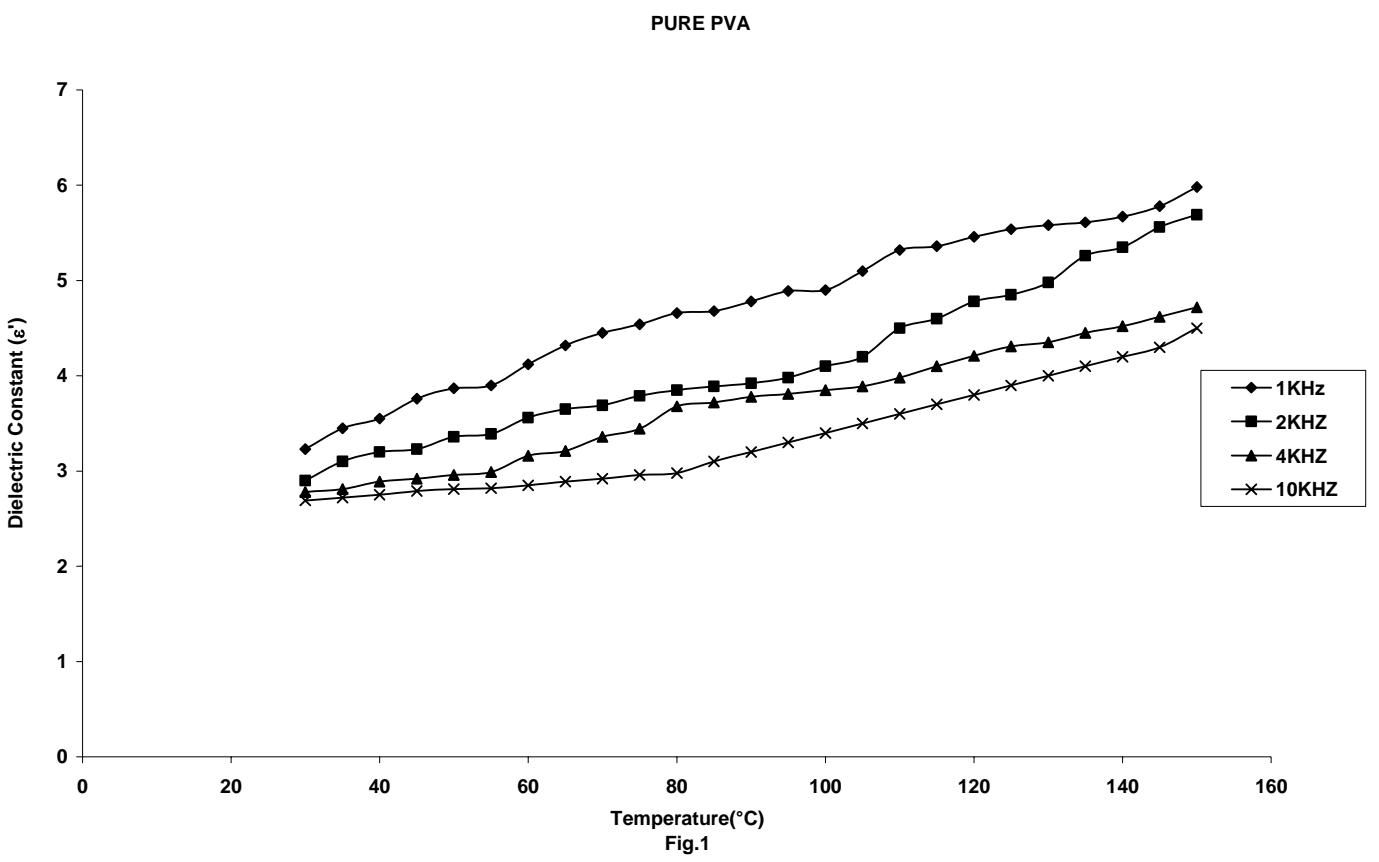

Fig. 1 variation of dielectric constant with temperature of pure PVA at 1, 2, 4 and $10 \mathrm{kHz}$ frequencies.

Fig. 1(a) shows the variation of dielectric constant $\left(\varepsilon^{\prime}\right)$ with temperature for PVA $+1 \mathrm{wt} \%$ (untreated sisal fibre powder) composite film.

It has been observed that dielectric constant increased with increase of temperature and decreased with increase of frequency. This increase in dielectric constant was due to presence of water and impurities present in fiber and also due to mobility of water dipole. When the water content reduced then the value of dielectric constant decreased. The cellulosic hydroxyl groups in the fibre are relatively unreactive, due to the strong hydrogen bonds.

Fig. 1(b) shows the variation of dielectric constant $\left(\varepsilon^{\prime}\right)$ with temperature for PVA $+3 w t \%$ (untreated sisal fibre powder) composite film. It was observed that $\varepsilon$ ' increased with increase of temperature and decreased with increasing frequency. Dielectric constant $\left(\varepsilon^{\prime}\right)$ value of these samples was higher as compared to pure PVA. This increase in $\varepsilon$ ' on adding sisal is due to the presence of impurities, lignin and cellulosic group and water dipoles present in sisal fibers. Lignin structure is amorphous in nature and cellulose is a straight chain polymer and crystalline in nature . Dielectric constant increases with increase in fibre content because of the increment in number of polar groups after the addition of hydrophilic lignocellulosic fibers. Fig. 1(c) shows the variation of $\varepsilon^{6}$ with temperature PVA $+5 \mathrm{wt} \%$ (untreated sisal fibre powder) composite film at $1,2,4$ and $10 \mathrm{kHz}$ frequencies. There is an increase in $\varepsilon$ ' at all the temperatures and decrease with frequency. Fig. 1(d) and 1(e) shows the variation of dielectric constant $(\varepsilon ')$ with temperature for $\mathrm{PVA}+1 \mathrm{wt} \%(5 \% \mathrm{NaOH}$ treated sisal fibre powder) composite film and $\mathrm{PVA}+3 \mathrm{wt} \%(5 \% \mathrm{NaOH}$ treated sisal fibre powder) composite film at $1,2,4$ and $10 \mathrm{kHz}$ frequencies respectively .It was observed that increase of temperature increased the $\varepsilon$ ' values at all temperatures. The dielectric constant of polymeric materials depends on the contribution of interfacial, dipole, and electronic and atomic polarization. NaoH treatment destroys the hydrogen bonding in cellulose hydroxyl groups; thereby making them more reactive .As a result of chemical treatment, the hydrophobicity of the fibre is increased. The improved interaction between the sisal fibre and the PVA in the case of these chemical modifications reduces the hydrophilicity of the composite, which, in turn, reduces the orientation polarization. The orientation polarization decreases considerably because of the decrease in water content in the fibre and hence the dielectric constant values also decrease. 
PVA +1\% Untreated Sisal Powder Fibre

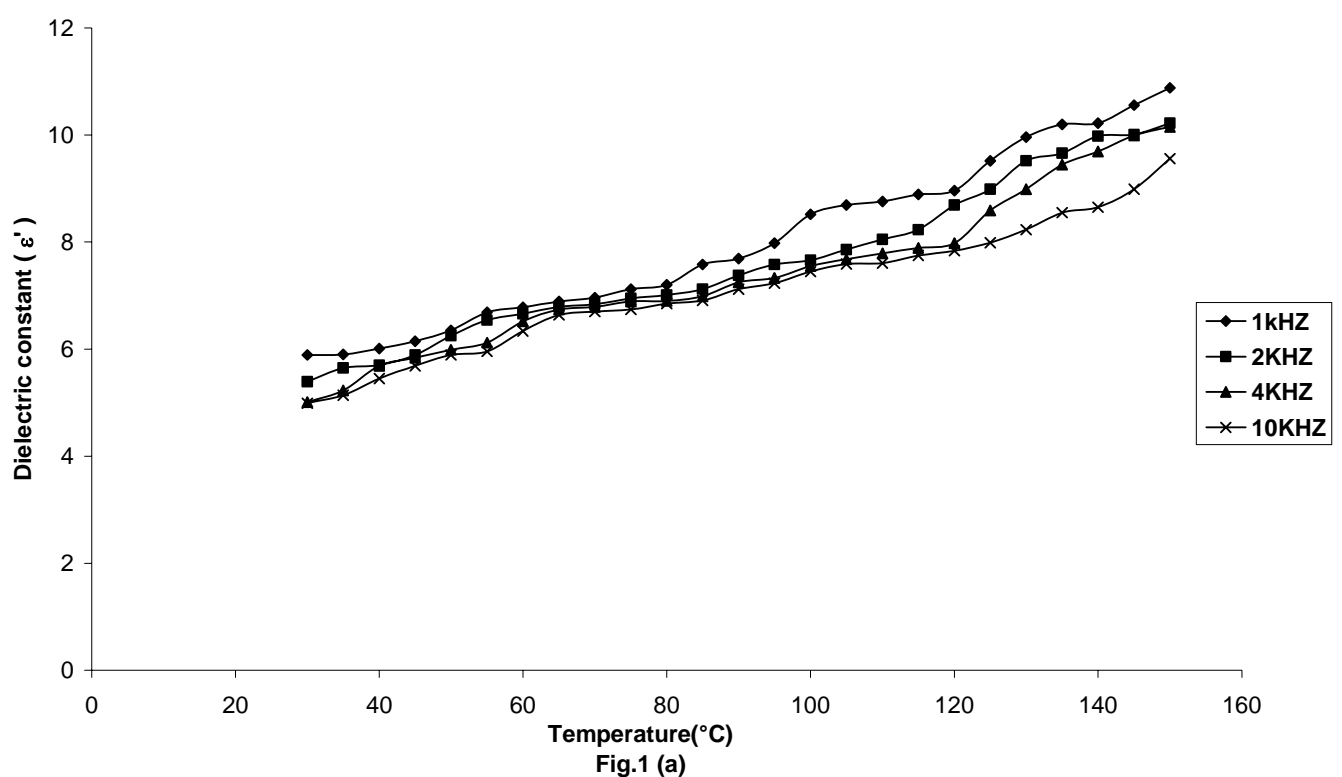

Fig. 1(a) variation of dielectric constant with temperature for PVA+1wt $\%$ (untreated sisal fibre powder) composite film at 1,2, 4 and $10 \mathrm{kHz}$ frequencies.

PVA +3\% Untreated Sisal Fibre Powder
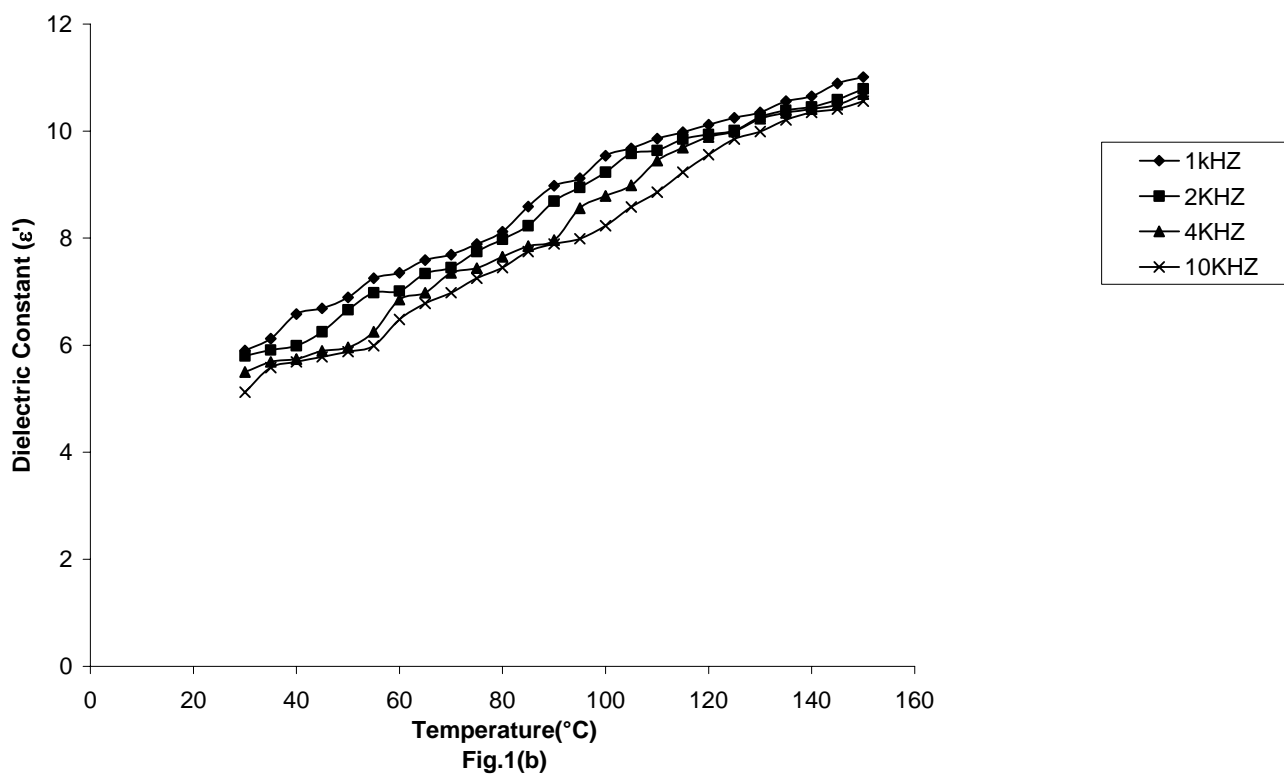

Fig. 1(b) variation of dielectric constant with temperature for PVA $+3 w t \%$

(untreated sisal fibre powder) composite film composite film at 1, 2, 4 and $10 \mathrm{kHz}$ frequencies.

Fig. 1(f) shows the variation of $\varepsilon^{6}$ with temperature PVA $+5 \mathrm{wt} \%(5 \% \mathrm{NaOH}$ treated sisal fibre powder)composite film at $1,2,4$ and $10 \mathrm{kHz}$ frequencies. It was observed that $\mathrm{NaOH}$ treated samples were having the low dielectric constant as compared to the untreated sisal fibre powder samples and pure PVA. The behaviour at low frequencies can be explained by assuming interfacial polarization. This type of polarization resulted due to the heterogeneity present as impurity in the composite material. Interfacial polarization decreases with increasing frequency and it influences the low frequency dielectric properties. It is observed that the treated samples are having the lower dielectric constant compare with the untreated composite. The main reason for this is the decrement of the orientation polarization due to the less interaction between the water molecules and polar $-\mathrm{OH}$ groups of sisal 
fibre powder. Due to this chemical treatment of sisal fibre powder, hydrophobic nature of sisal fibre powder increases, causing reduction of the moisture absorption (Miah et al., 2005). It was seen that the dielectric constant of untreated sisal composite is higher due to the presence of natural fiber in composite materials increases the air content of a composite because the hollow space created in the middle of each fiber. The air trapped in this middle portion results in higher dielectric constant (Maya et al., 2006). Fig.2 shows the variation of $\tan \delta$ with temperature for pure PVA. It was observed that $\tan \delta$ increased with increase in temperature but decreases with increasing frequency.

\section{PVA+5\% UnTreated Sisal Fibre powder}

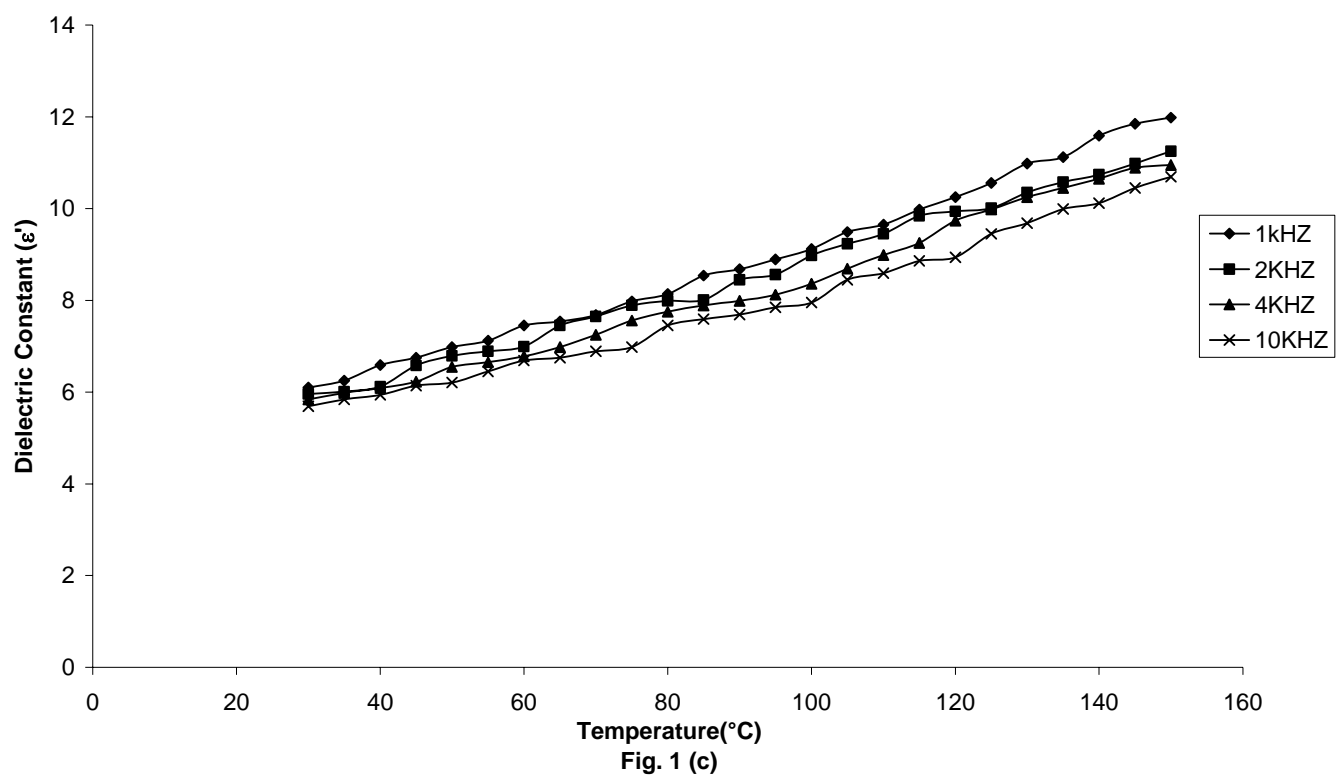

Fig. 1(c) variation of dielectric constant with temperature PVA $+5 \mathrm{wt} \%$ (untreated sisal fibre powder) composite film at 1, 2, 4 and $10 \mathrm{kHz}$ frequencies.

PVA $+\mathbf{1} \% \mathrm{NaoH}$ treated Sisal Fibre Powder

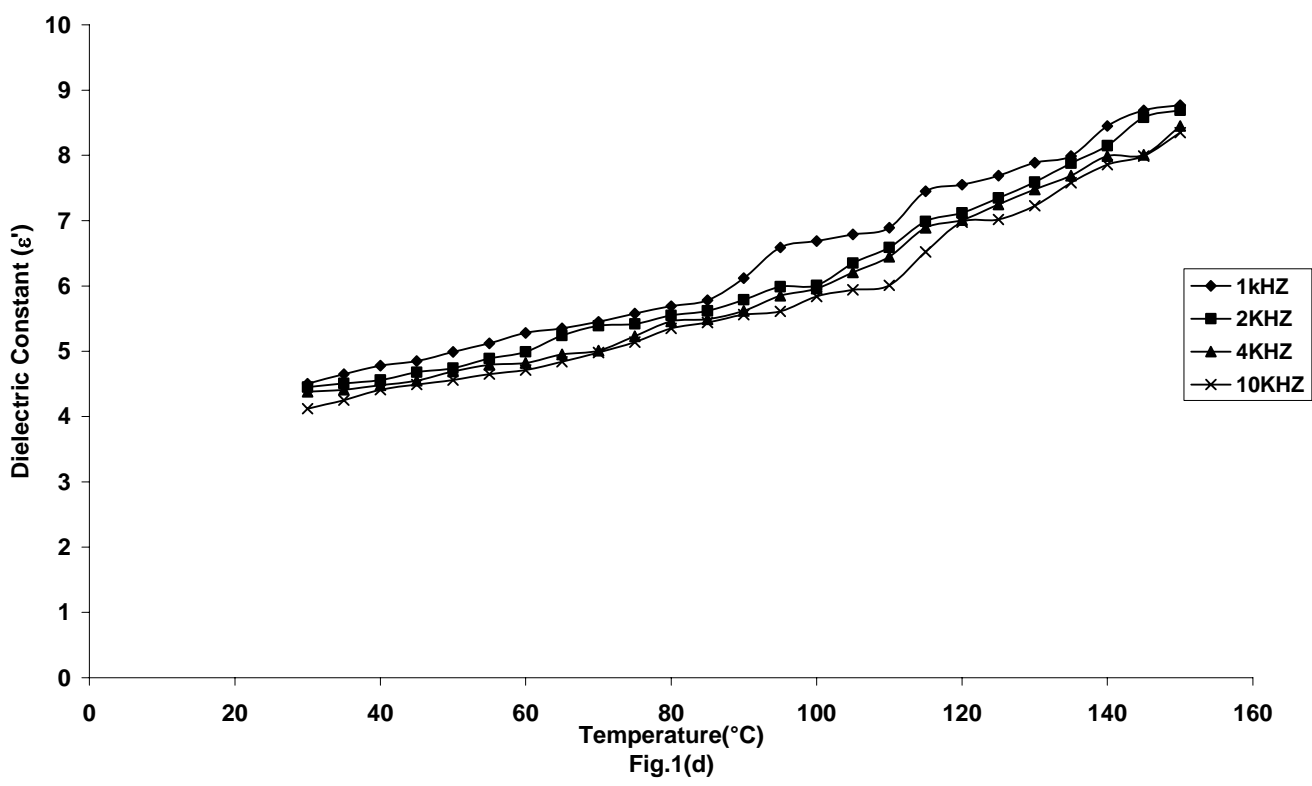

Fig. 1(d) variation of dielectric constant with temperature for PVA $+1 \mathrm{wt} \%$ $(5 \% \mathrm{NaOH}$ treated sisal fibre powder) composite film at $1,2,4$ and $10 \mathrm{kHz}$ frequencies. 
Figs.2 (a-c) show the variation of $\tan \delta$ with temperature for $1,3 \& 5 \mathrm{wt} \%$ untreated sisal powder filled PVA composites film at $1,2,4$ and $10 \mathrm{kHz}$ frequencies. These plots show that $\tan \delta$ increased with increase in temperature but decreases with increasing frequency for all the samples. The increase in dissipation factor with increase in filler concentration is due to the interfacial polarization mechanism occurred in the composites corresponding to $1,2,4$ and $10 \mathrm{kHz}$ frequencies.

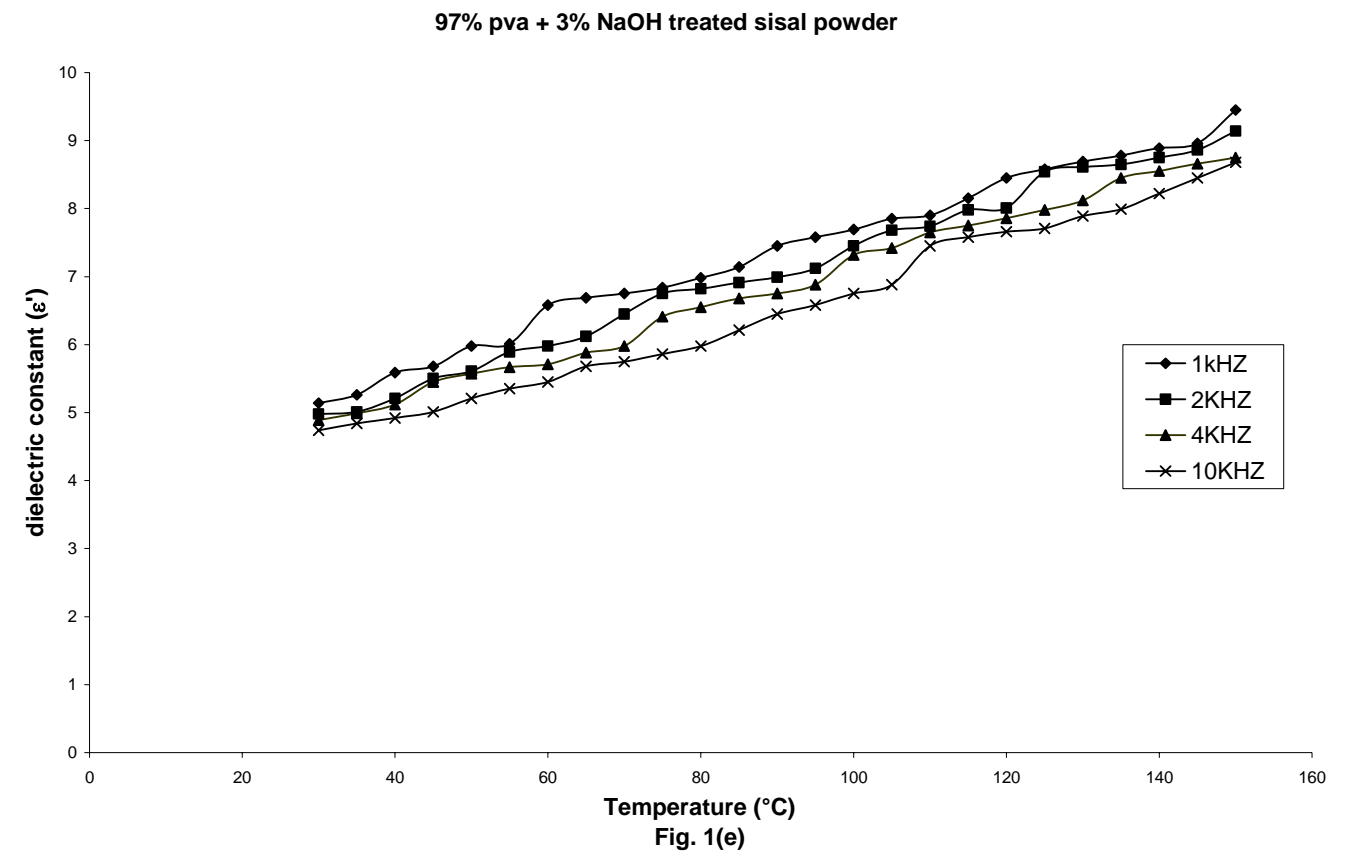

Fig. 1(e) variation of dielectric constant with temperature for PVA $+3 \mathrm{wt} \%$

$(5 \% \mathrm{NaOH}$ treated sisal fibre powder) composite film at $1,2,4$ and $10 \mathrm{kHz}$ frequencies.

PVA+ 5\% Treated Sisal Fibre powder

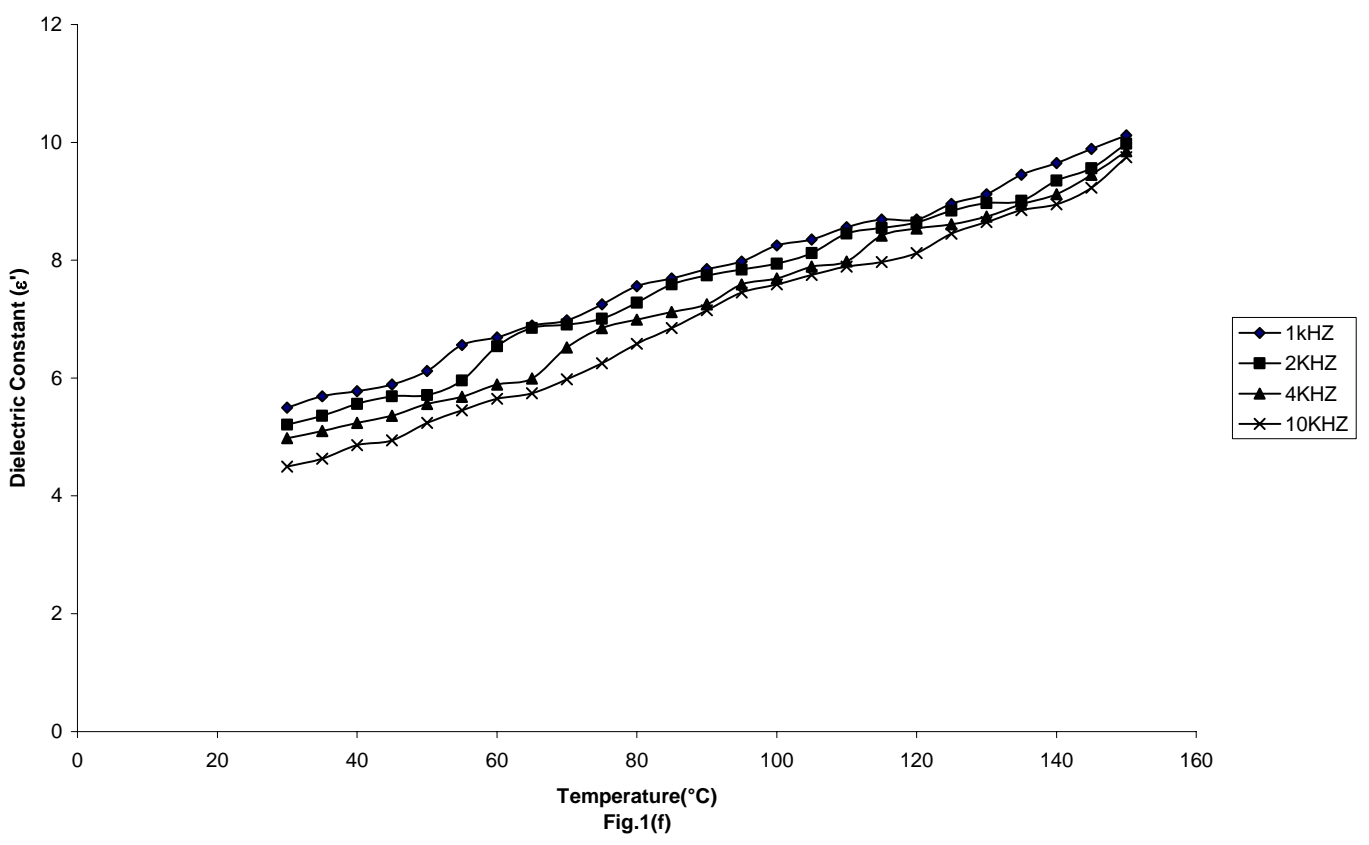

Fig. 1(f) variation of dielectric constant with temperature PVA $+5 \mathrm{wt} \%(5 \% \mathrm{NaOH}$ treated sisal fibre powder) composite film at 1 , 2,4 and $10 \mathrm{kHz}$ frequencies. 


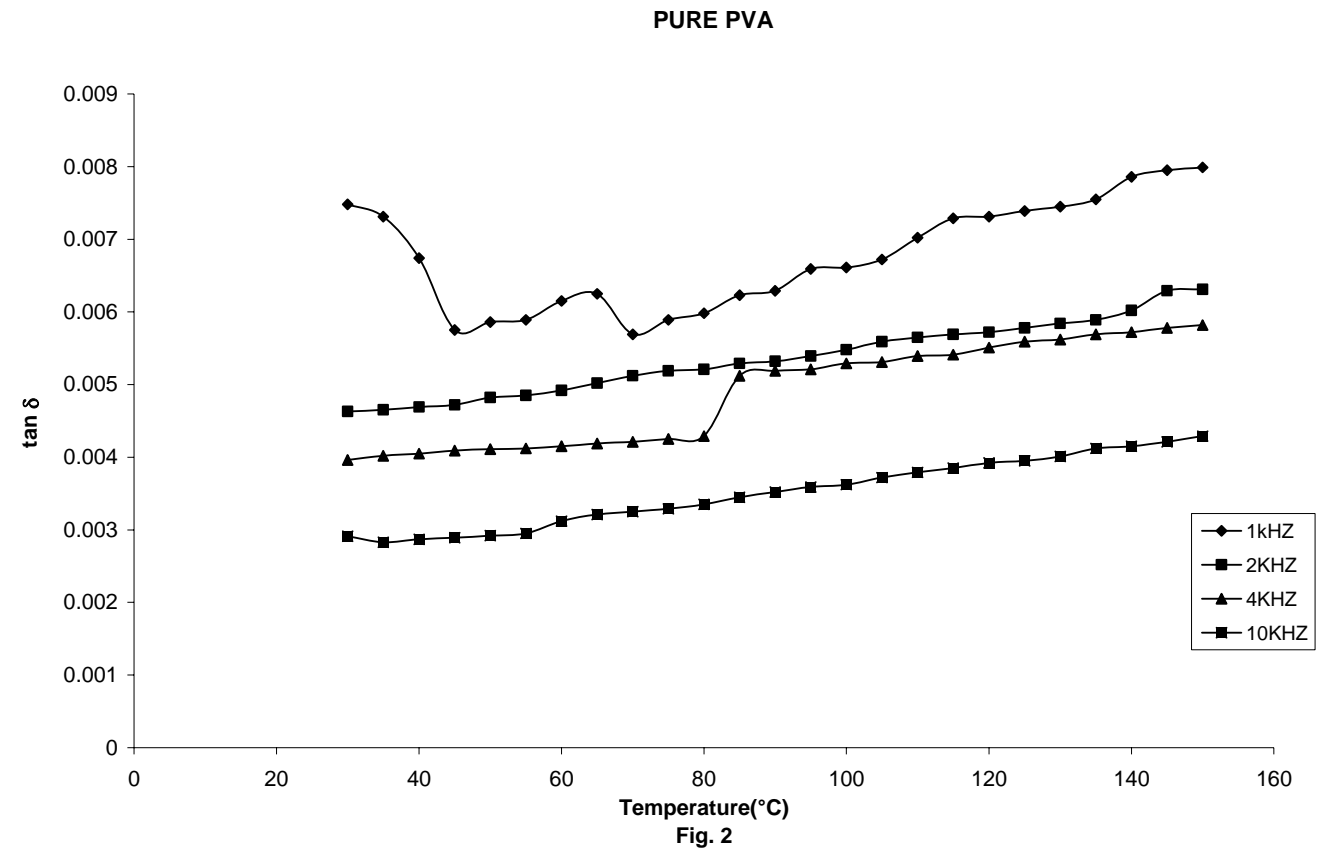

Fig. 2 variation of $\tan \delta$ with temperature of pure PVA at 1,2, 4 and $10 \mathrm{kHz}$ frequencies.

PVA+1\% Untreated sisal powder

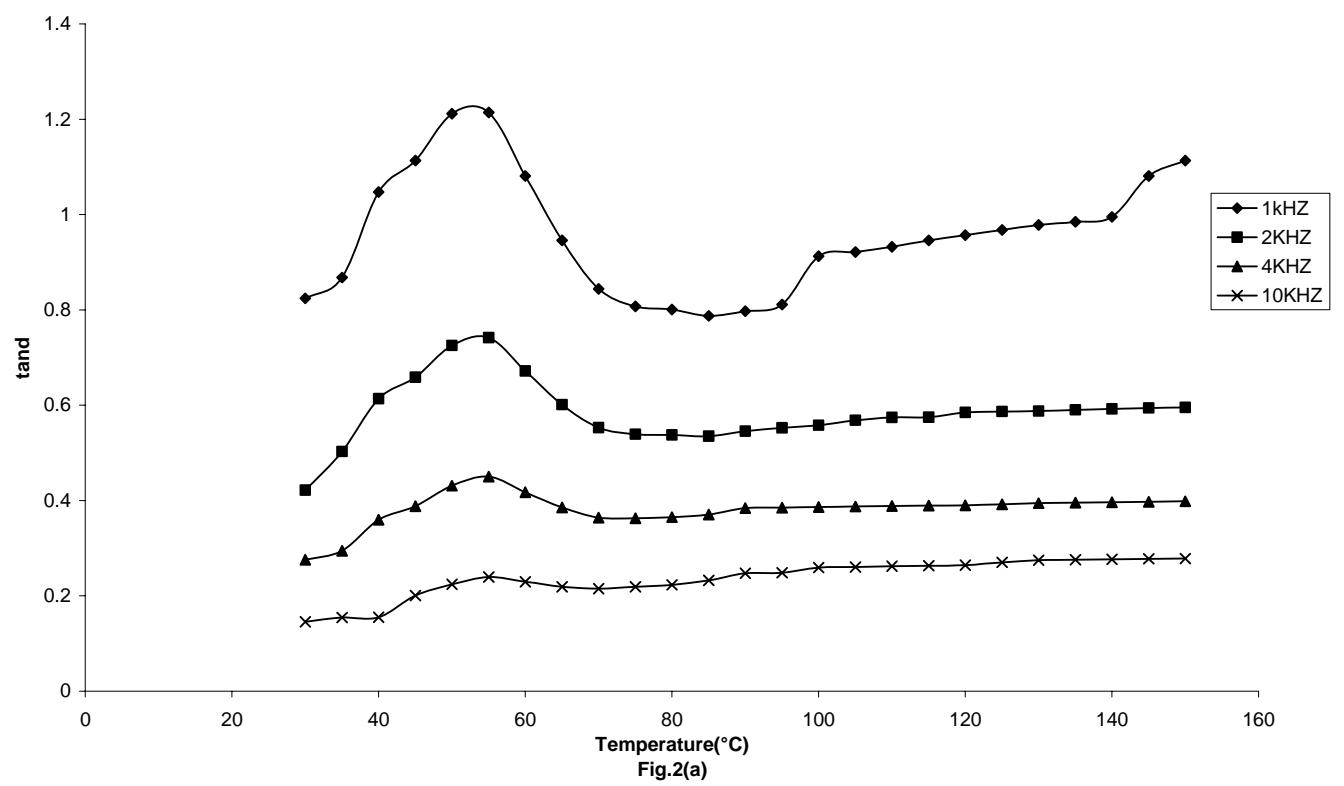

Fig. 2(a) variation of $\tan \delta$ with temperature for PVA $+1 \mathrm{wt} \%$ (untreated sisal fibre powder) composite film at 1,2, 4 and $10 \mathrm{kHz}$ frequencies.

Figs. 2(d-f) shows the variation of tan $\delta$ with temperature for $1,3 \& 5 \mathrm{wt} \%$ treated sisal powder filled PVA composites at $1,2,4$ and $10 \mathrm{kHz}$ frequencies. In the case of Fig.2 (a), the first tan $\delta$ peak appeared at $50^{\circ} \mathrm{C}$ for all the frequencies and another peak at $100^{\circ} \mathrm{C}$ also appeared at $1 \mathrm{KHz}$ frequency. In case of Fig. 2 (d), first $\tan \delta$ peak appeared at $65^{\circ} \mathrm{C}$ corresponding to $1 \mathrm{kHz}$ frequency. Another peak appeared between $110^{\circ} \mathrm{C}$ and $120^{\circ} \mathrm{C}$ at 4 and $10 \mathrm{KHz}$ frequencies. The dissipation factor attained high values between $145^{\circ} \mathrm{C}$ and $150^{\circ} \mathrm{C}$, The decrease in peak height with increasing frequency, is attributed to the relaxation behaviour. Relaxation time determined for filler filled PVA composite film at $70^{\circ} \mathrm{C}$ is listed in Table 1, which shows an increase with increase of filler content. This is attributed to the hindrance created by the presence of filler particles in the path of dipole rotation. It shows that the addition of treated sisal fibre increases the relaxation time. Better bonding between fibre and PVA would have created hindrance in the movement of the dipoles and hence increased the relaxation time. 
Table 1.Relaxation-time value calculated for sisal- PVA composites

\begin{tabular}{|l|l|l|l|l|l|l|l|}
\hline $\begin{array}{l}\text { Temperature } \\
\left({ }^{\circ} \mathrm{C}\right)\end{array}$ & $\begin{array}{l}\text { PURE } \\
\text { PVA }\end{array}$ & $\begin{array}{l}\text { PVA+1wt } \% \text { un } \\
\text { treated } \\
\text { sisalfibre } \\
\text { powder } \\
\text { composite }\end{array}$ & $\begin{array}{l}\text { PVA+3wt } \% \\
\text { un treated } \\
\text { sisal fibre } \\
\text { powder } \\
\text { composite }\end{array}$ & $\begin{array}{l}\text { PVA+5wt } \% \\
\text { un treated } \\
\text { sisal fibre } \\
\text { powder } \\
\text { composite }\end{array}$ & $\begin{array}{l}\text { PVA+1wt\% } \\
(5 \% \mathrm{NaOH} \\
\text { treated sisal } \\
\text { fibre } \\
\text { powder }) \\
\text { composite }\end{array}$ & $\begin{array}{l}\mathrm{PVA}+3 \mathrm{wt} \% \\
(5 \% \mathrm{NaOH} \\
\text { Treated } \\
\text { sisal fibre } \\
\text { powder }) \\
\text { composite }\end{array}$ & $\begin{array}{l}\mathrm{PVA}+5 \mathrm{wt} \% \\
(5 \% \mathrm{NaOH} \\
\text { treated } \\
\text { sisal fibre } \\
\text { powder }) \\
\text { composite }\end{array}$ \\
\hline $70{ }^{\circ} \mathrm{C}$ & $2.36 \mathrm{E}-04$ & $2.14 \mathrm{E}-06$ & $9.34 \mathrm{E}-08$ & $8.387 \mathrm{E}-07$ & $9.59 \mathrm{E}-08$ & $9.39 \mathrm{E}-08$ & $8.38 \mathrm{E}-08$ \\
\hline
\end{tabular}

Fig. 3 shows the variation of dielectric loss with temperature for pure PVA film at 1, 2, 4 and $10 \mathrm{kHz}$ frequencies. It is observed that dielectric loss increased with increasing temperature and decreased with increasing frequency. Figs. 3(a-c) show the variation of dielectric loss with temperature for $1,3 \& 5 \mathrm{wt} \%$ un treated sisal powder filled PVA composites at $1,2,4 \mathrm{and} 10 \mathrm{kHz}$ frequencies. Figs. 3(d-f) show the variation of dielectric loss with temperature for $1,3 \& 5 \mathrm{wt} \%$ treated sisal powder filled PVA composites at 1, 2, 4 and $10 \mathrm{kHz}$ frequencies. Fig. 4 shows the variation of a.c. conductivity with temperature for pure PVA film at 1,2, 4 and $10 \mathrm{kHz}$ frequencies. Fig. 4(a) shows the variation of a.c. conductivity with temperature for PVA+1wt $\%$ (untreated sisal fibre powder) composite film at $1,2,4$ and $10 \mathrm{kHz}$ frequencies. It was observed that a. c. conductivity increased with increasing temperature and frequency. The increase in a.c. conductivity with temperature indicates that there may be charge carriers, which would have transported by hopping through the defect sites along the polymer chain. Fig. 4(b) shows the variation of a.c. conductivity with temperature for PVA $+3 \mathrm{wt} \%$ (untreated sisal fibre powder) composite film at $1,2,4 \mathrm{and} 10 \mathrm{kHz}$ frequencies. Fig. 4(c) shows the variation of a.c. conductivity with temperature for PVA $+5 \mathrm{wt} \%$ (untreated sisal fibre powder) composite film at 1, 2, 4 and $10 \mathrm{kHz}$ frequencies. Fig. 4(d) shows the variation of a.c. conductivity with temperature for $\mathrm{PVA}+1 \mathrm{wt} \%(5 \% \mathrm{NaOH}$ treated sisal fibre powder) composite film at 1, 2, 4 and $10 \mathrm{kHz}$ frequencies. Fig. 4(e) shows the variation of a.c. conductivity with temperature for $\mathrm{PVA}+3 \mathrm{wt} \%(5 \% \mathrm{NaOH}$ treated sisal fibre powder) composite film at $1,2,4 \mathrm{and} 10 \mathrm{kHz}$ frequencies. Fig. $4(\mathrm{f})$ shows the variation of a.c. conductivity with temperature for $\mathrm{PVA}+5 \mathrm{wt} \%(5 \% \mathrm{NaOH}$ treated sisal fibre powder) composite film at 1,2, 4 and $10 \mathrm{kHz}$ frequencies.

The conductivity of insulating interlayer depends on its composition, thickness and on the material having particles in a complicated fashion. It was noticed that change in concentration of filler changes the conductivity, permittivity and $\tan \delta$ values.

\section{PVA+3\% Un treated Sisal Fibre Powder}

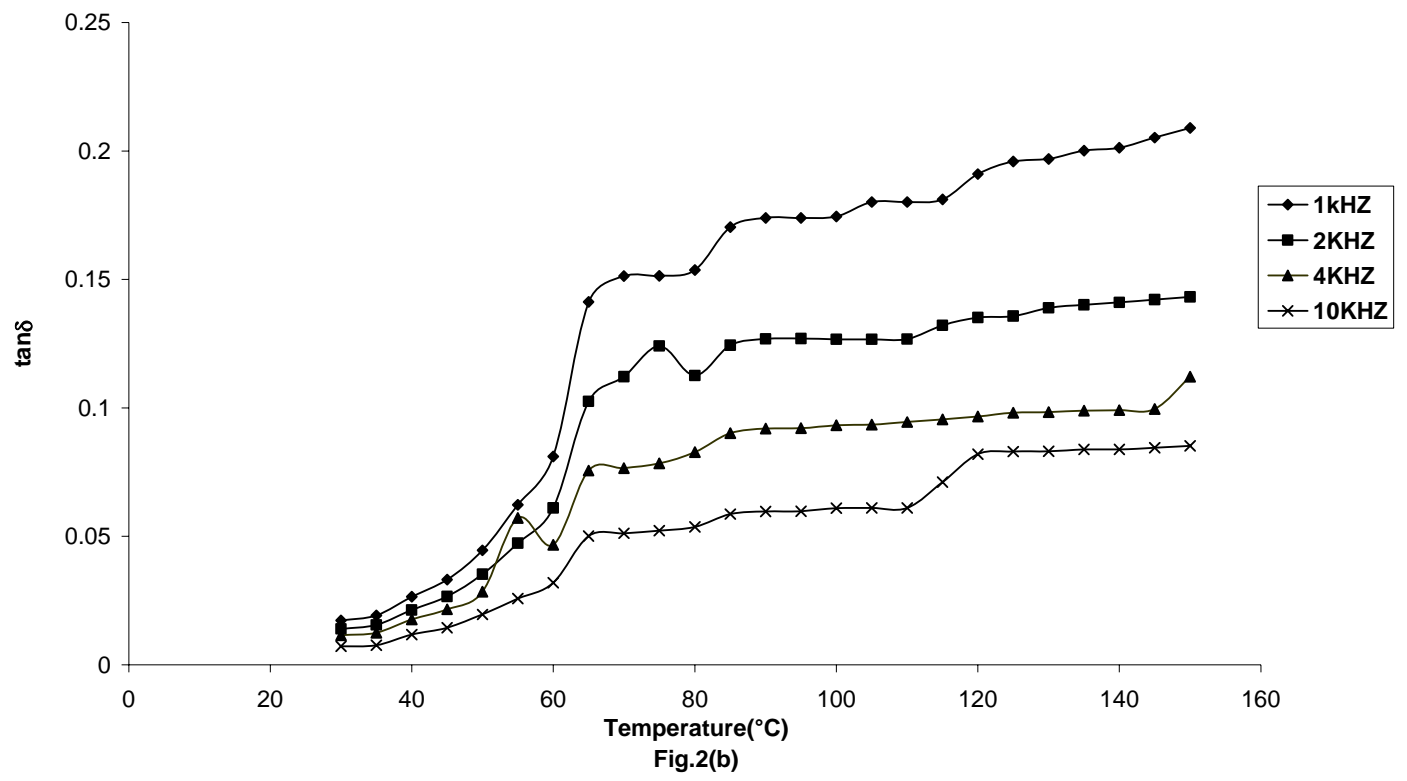

Fig. 2(b) variation of $\tan \delta$ with temperature for PVA $+3 \mathrm{wt} \%$

(untreated sisal fibre powder) composite film composite film at 1,2, 4 and $10 \mathrm{kHz}$ frequencies. 
PVA+ 5\% Untreated Sisal Powder

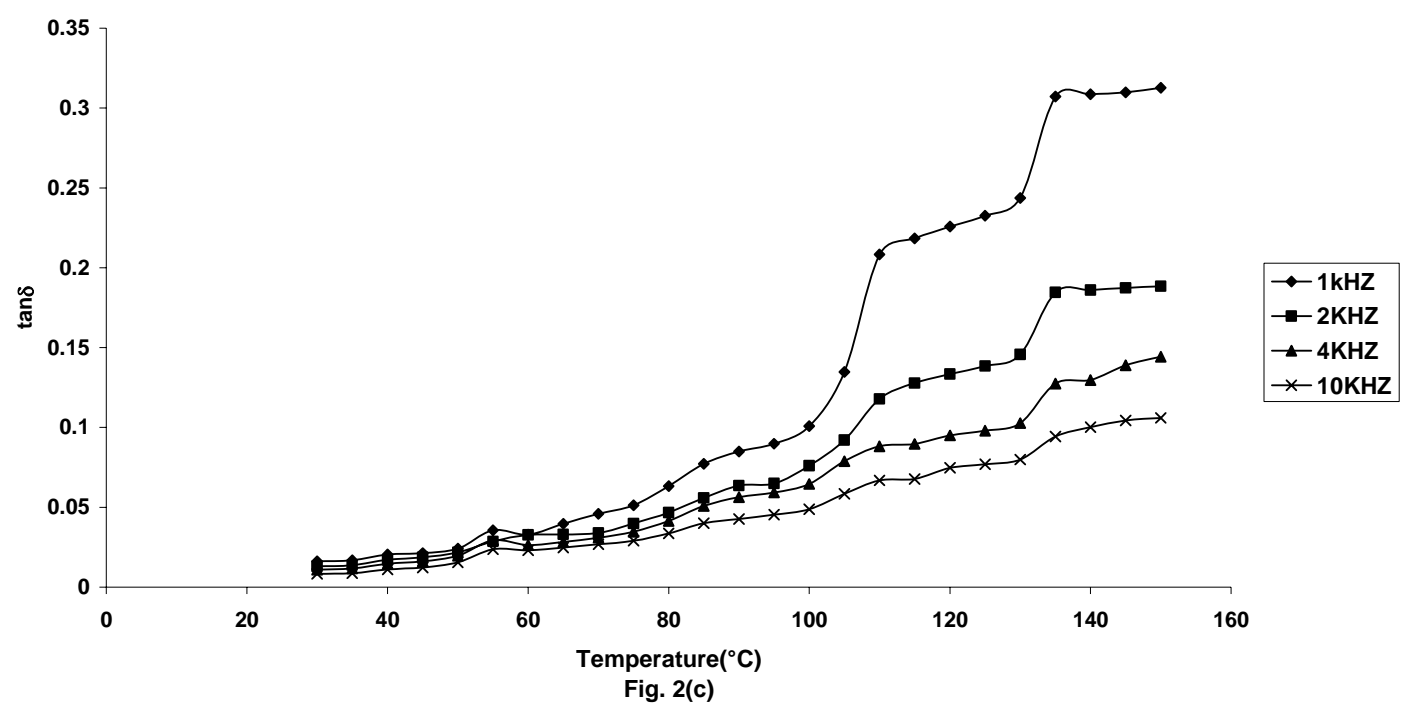

Fig. 2(c) variation of $\tan \delta$ with temperature PVA $+5 \mathrm{wt} \%$

(untreated sisal fibre powder) composite film at 1,2, 4 and $10 \mathrm{kHz}$ frequencies.

PVA+1\% NaoH Treated Sisal fibre powder

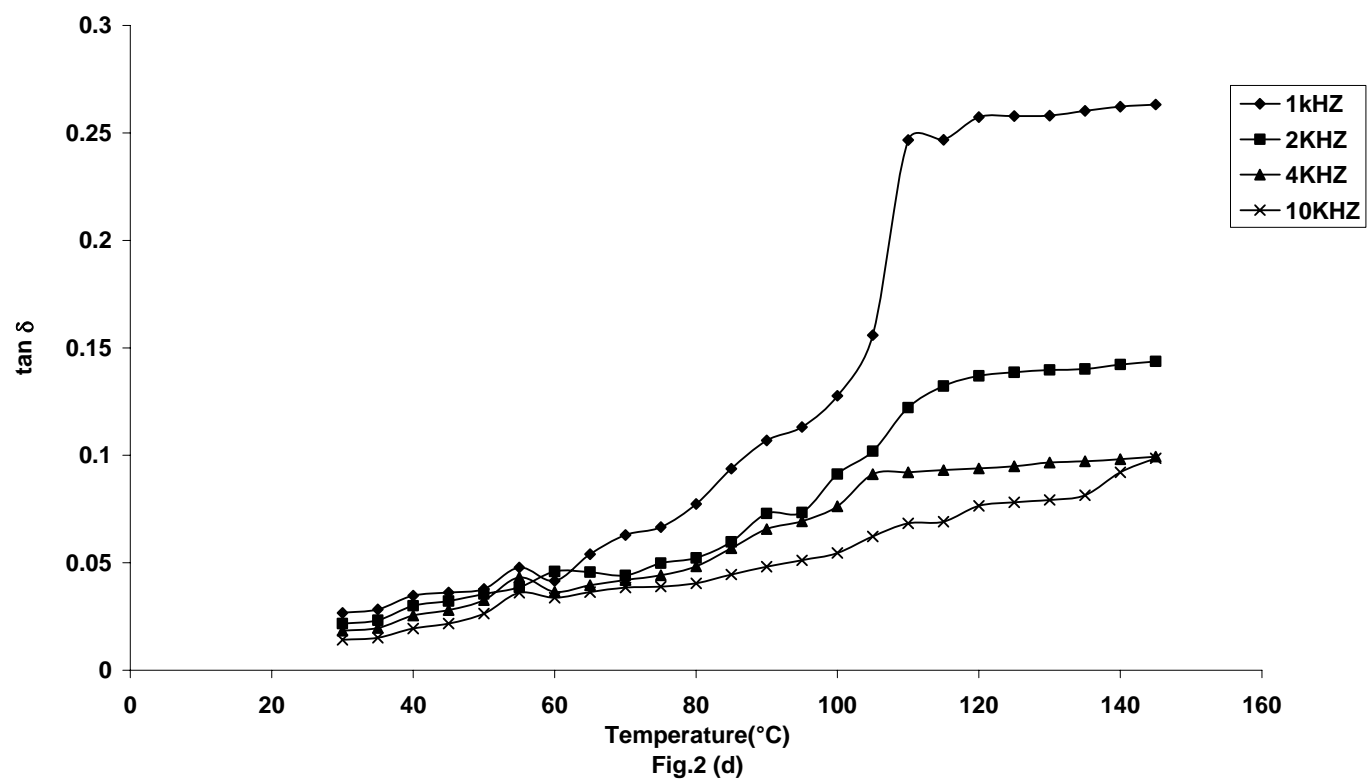

Fig. 2(d) variation of $\tan \delta$ with temperature for PVA $+1 \mathrm{wt} \%$

$(5 \% \mathrm{NaOH}$ treated sisal fibre powder) composite film at $1,2,4$ and $10 \mathrm{kHz}$ frequencies. 
Pva $+3 \%$ treated Sisal Powder

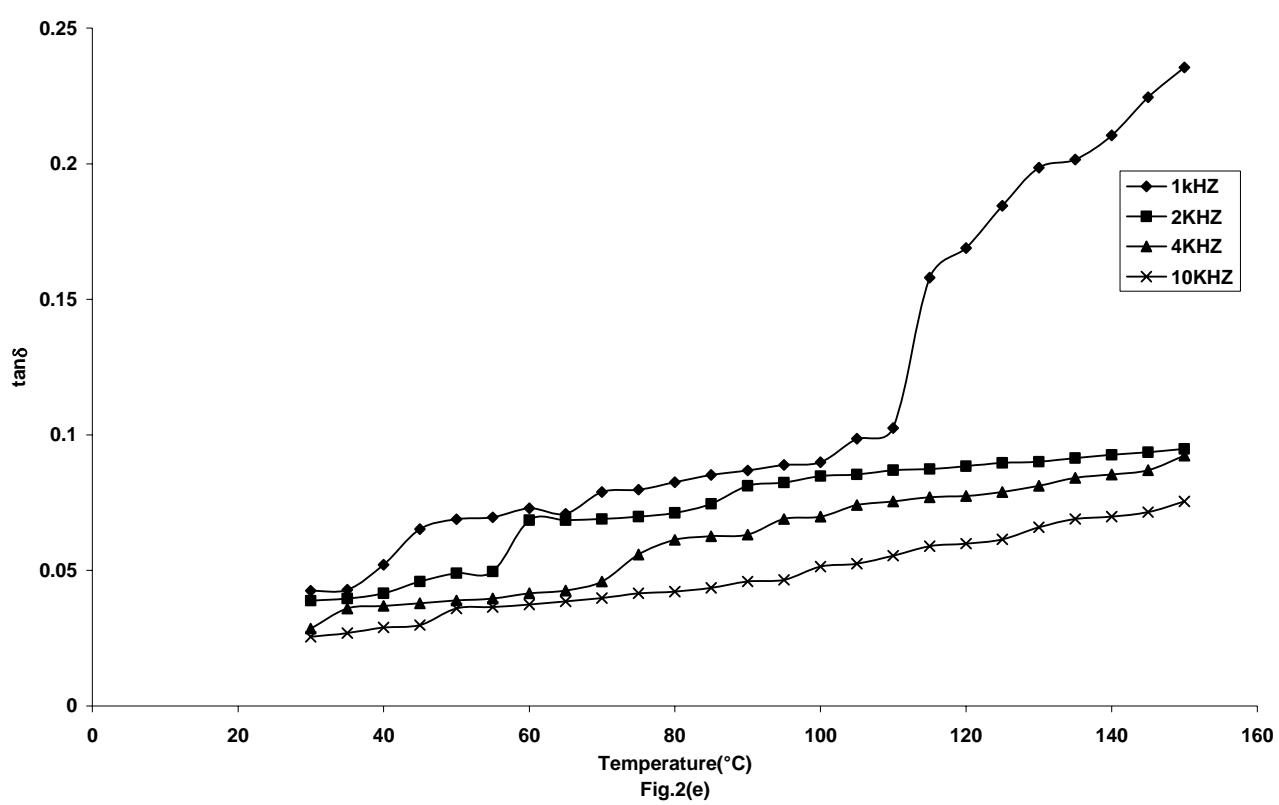

Fig. 2(e) variation of $\tan \delta$ with temperature for PVA $+3 \mathrm{wt} \%$

$(5 \% \mathrm{NaOH}$ treated sisal fibre powder) composite film at 1,2, 4 and $10 \mathrm{kHz}$ frequencies.

\section{PVA+5\% Treated Sisal Fibre Powder Tand}

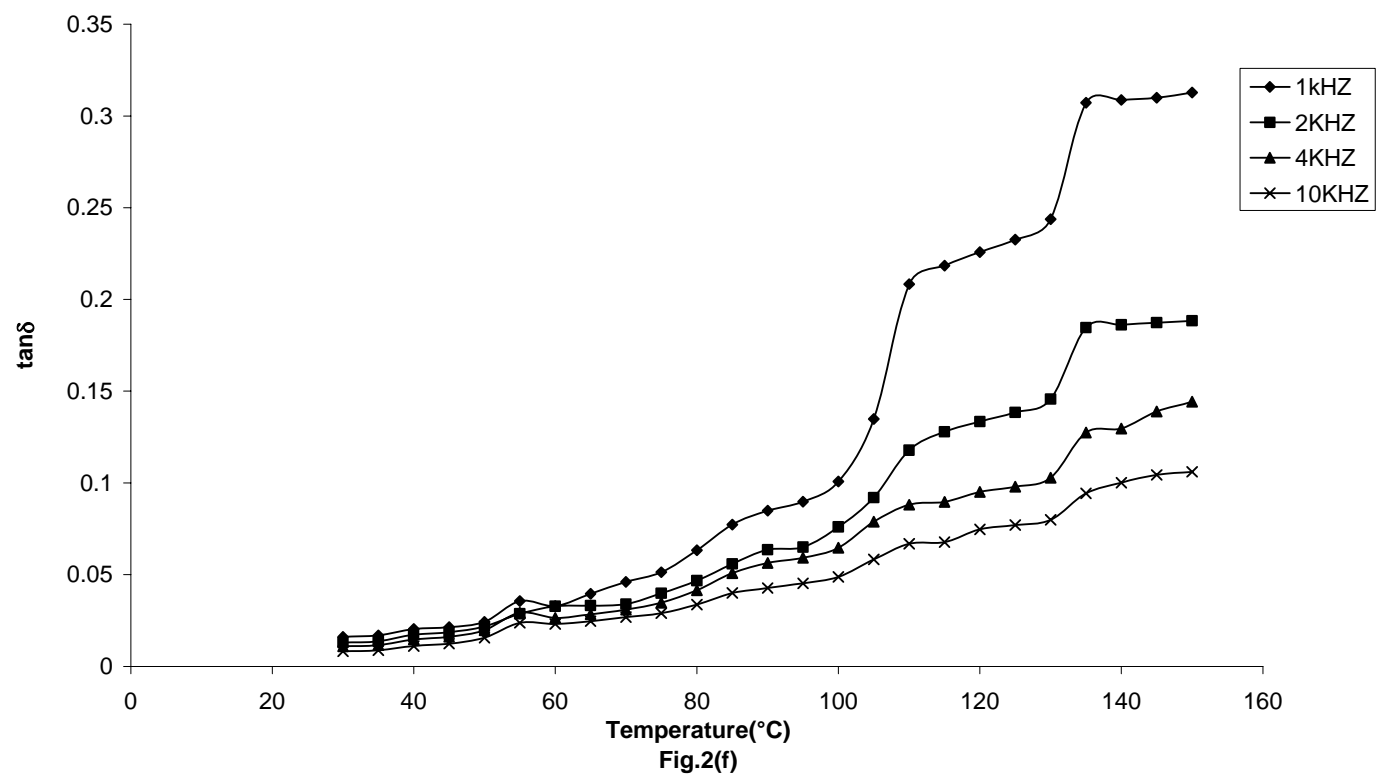

Fig. 2(f) variation of $\tan \delta$ with temperature $\mathrm{PVA}+5 \mathrm{wt} \%$

$(5 \% \mathrm{NaOH}$ treated sisal fibre powder) composite film at $1,2,4$ and $10 \mathrm{kHz}$ frequencies. 


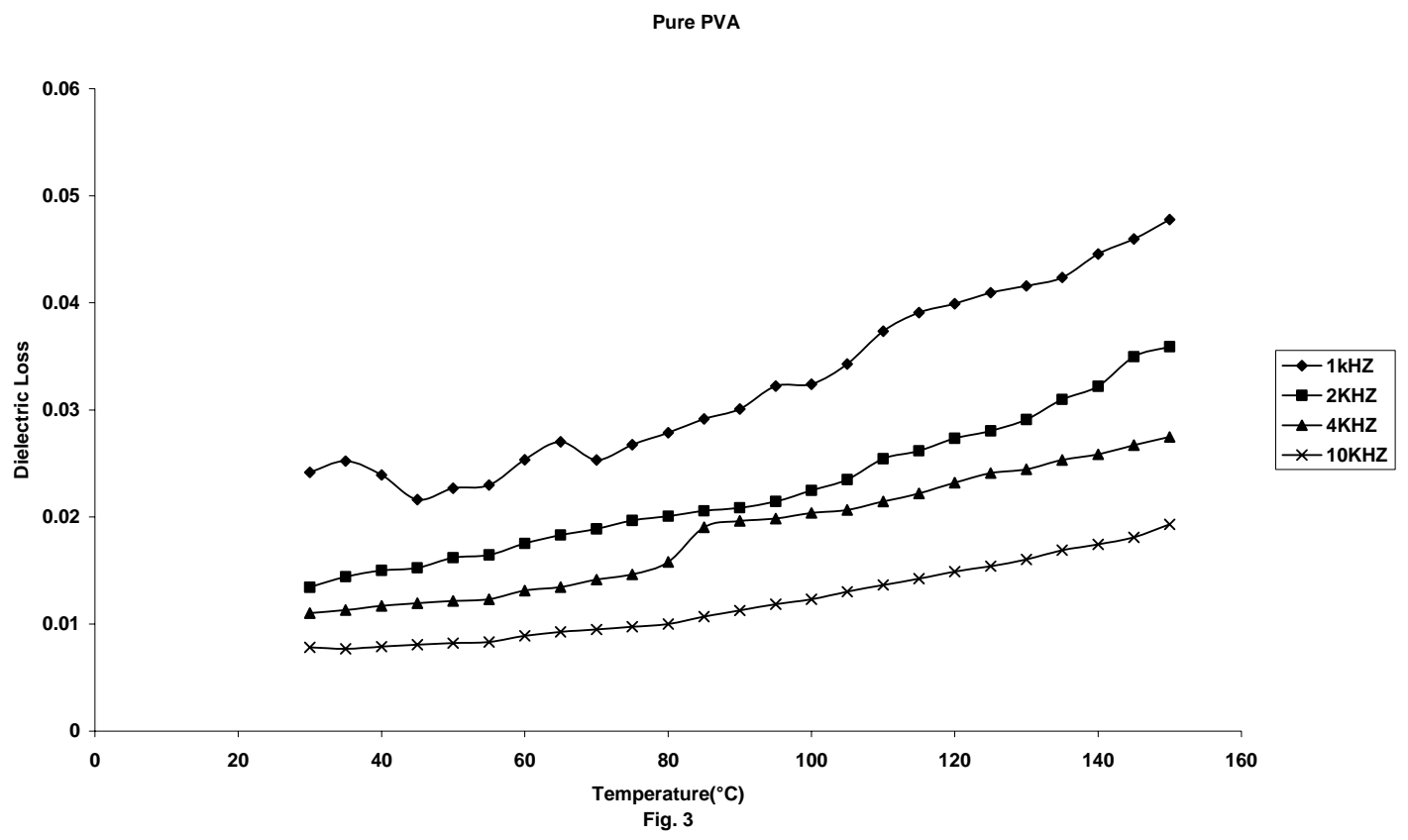

Fig. 3 variation of Dielectric Loss with temperature for pure PVA composite film at $1,2,4$ and $10 \mathrm{kHz}$ frequencies.

PVA+ $1 \%$ UTsisal fibre

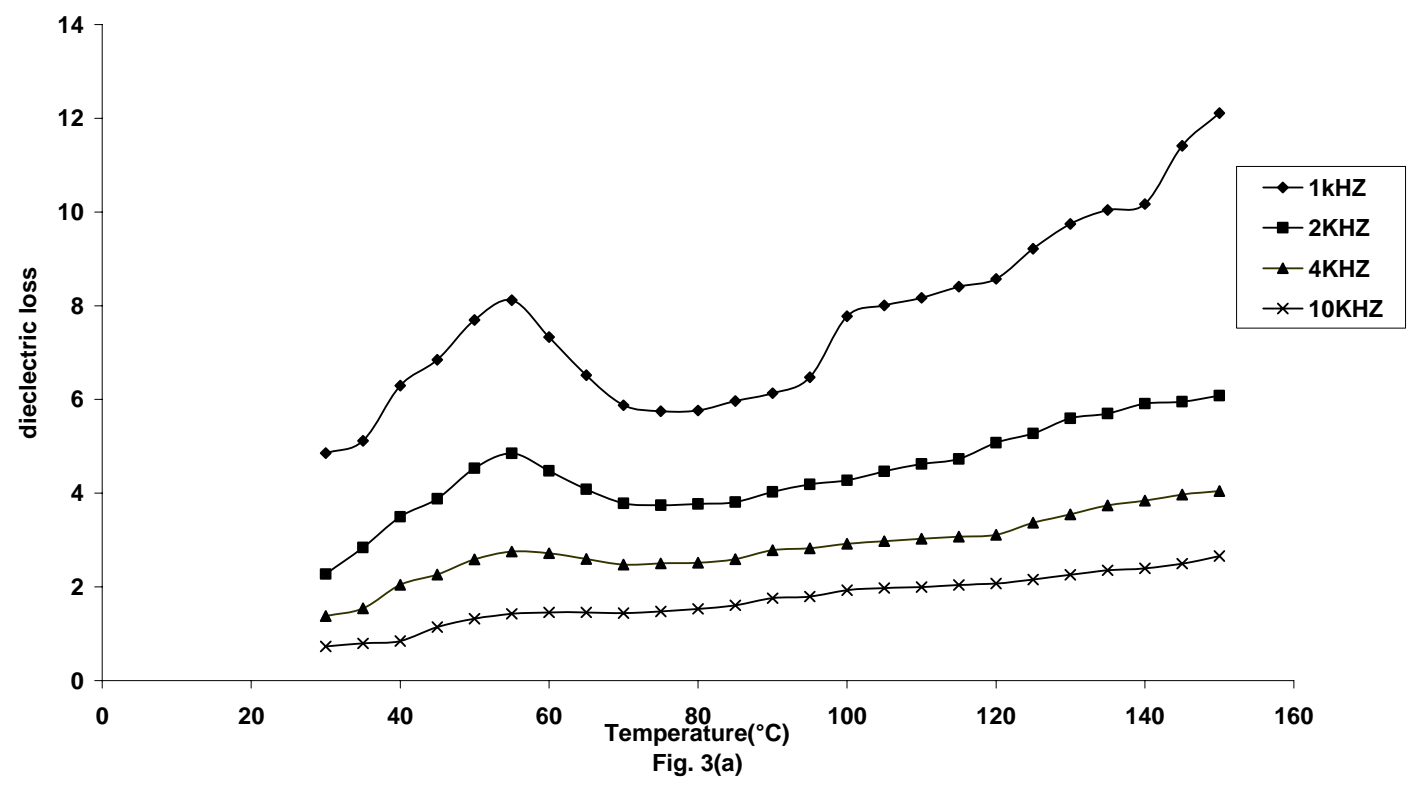

Fig. 3(a) variation of Dielectric Loss with temperature for PVA $+1 \mathrm{wt} \%$ (untreated sisal fibre powder) composite film at 1,2, 4 and $10 \mathrm{kHz}$ frequencies. 
PVA+3\% Untreated Sisal Fibre powder

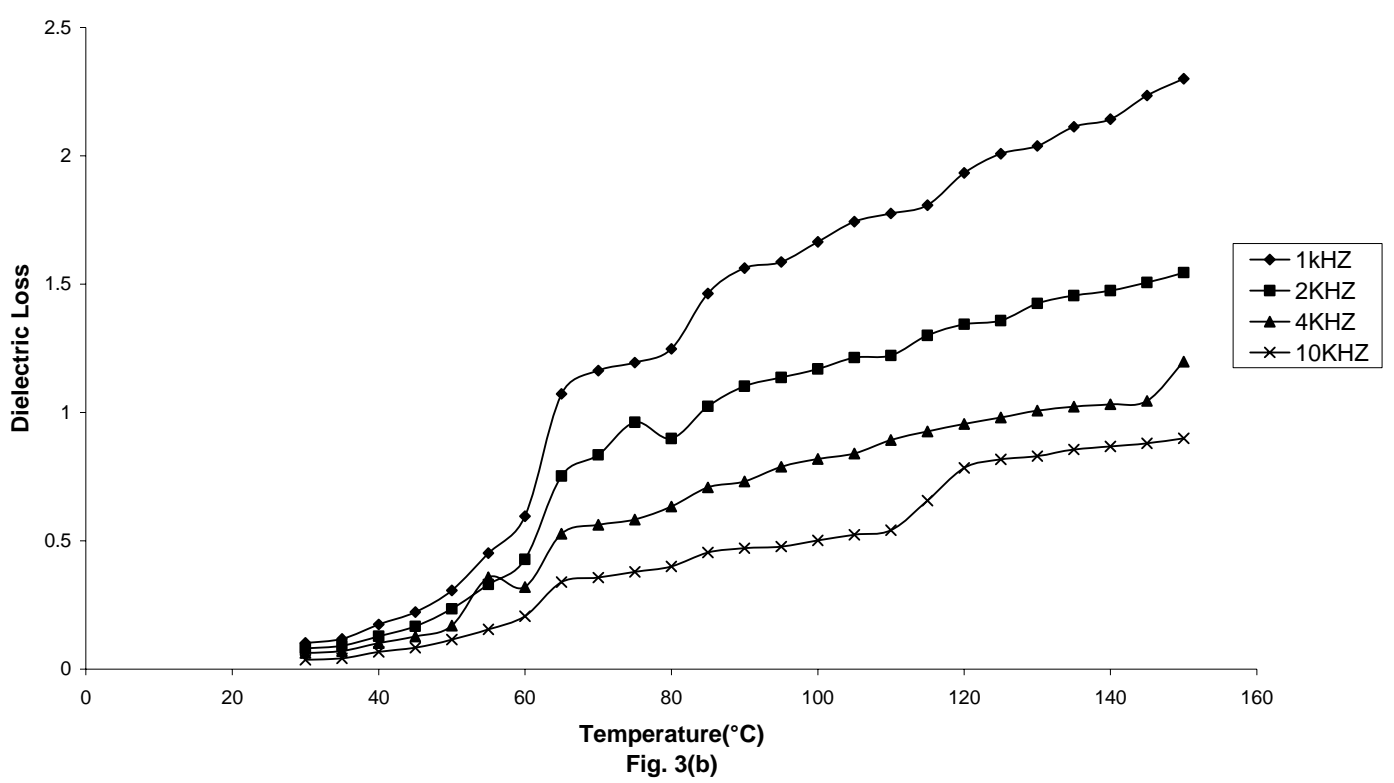

Fig. 3(b) variation of Dielectric Loss with temperature for PVA $+3 w t \%$ (untreated sisal fibre powder) composite film at 1,2, 4 and $10 \mathrm{kHz}$ frequencies.

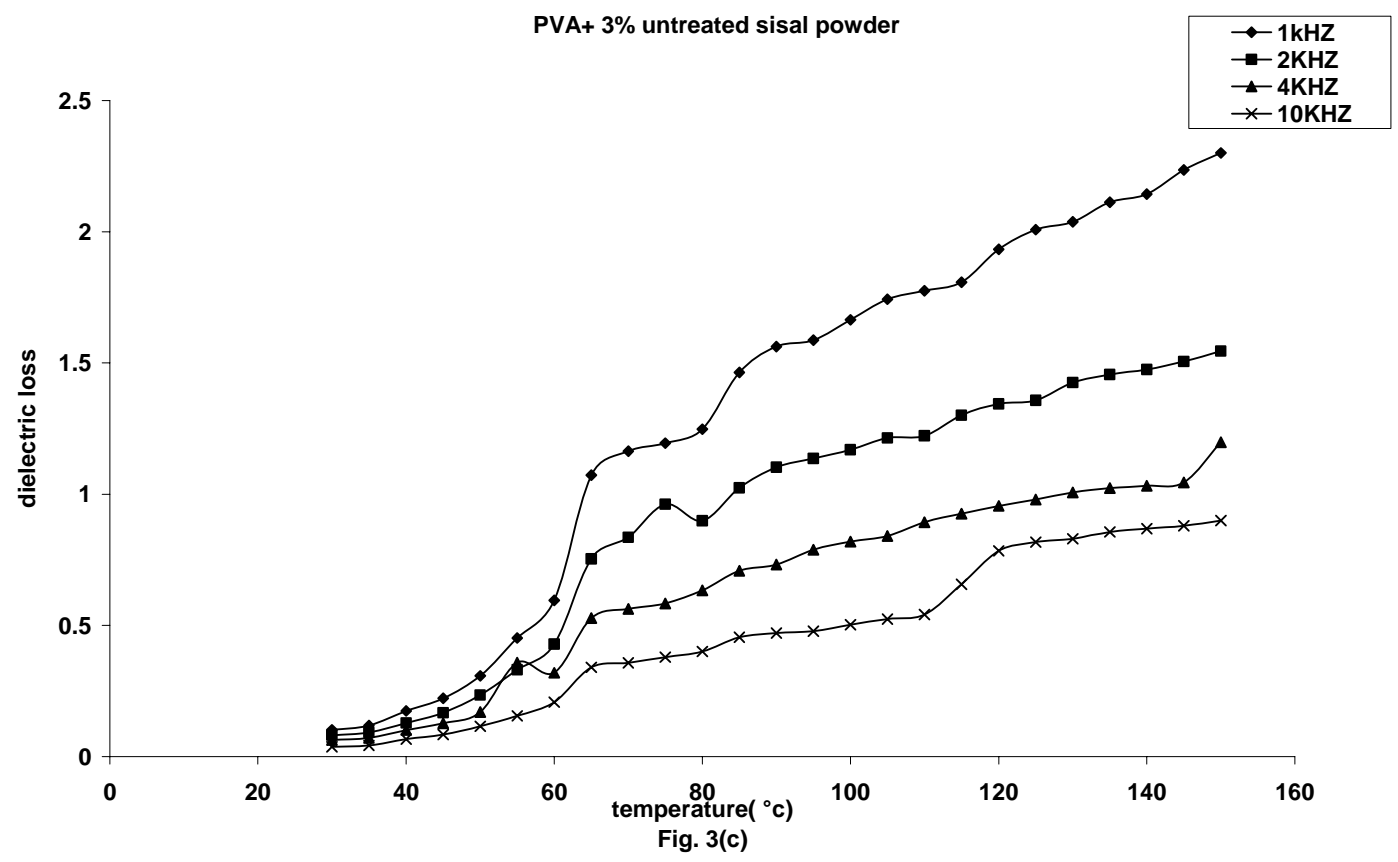

Fig. 3(c) variation of Dielectric Loss with temperature for PVA $+5 \mathrm{wt} \%$ (untreated sisal fibre powder) composite film at 1,2, 4 and $10 \mathrm{kHz}$ frequencies. 
PVA+ 1\% NaOH treated sisal powder

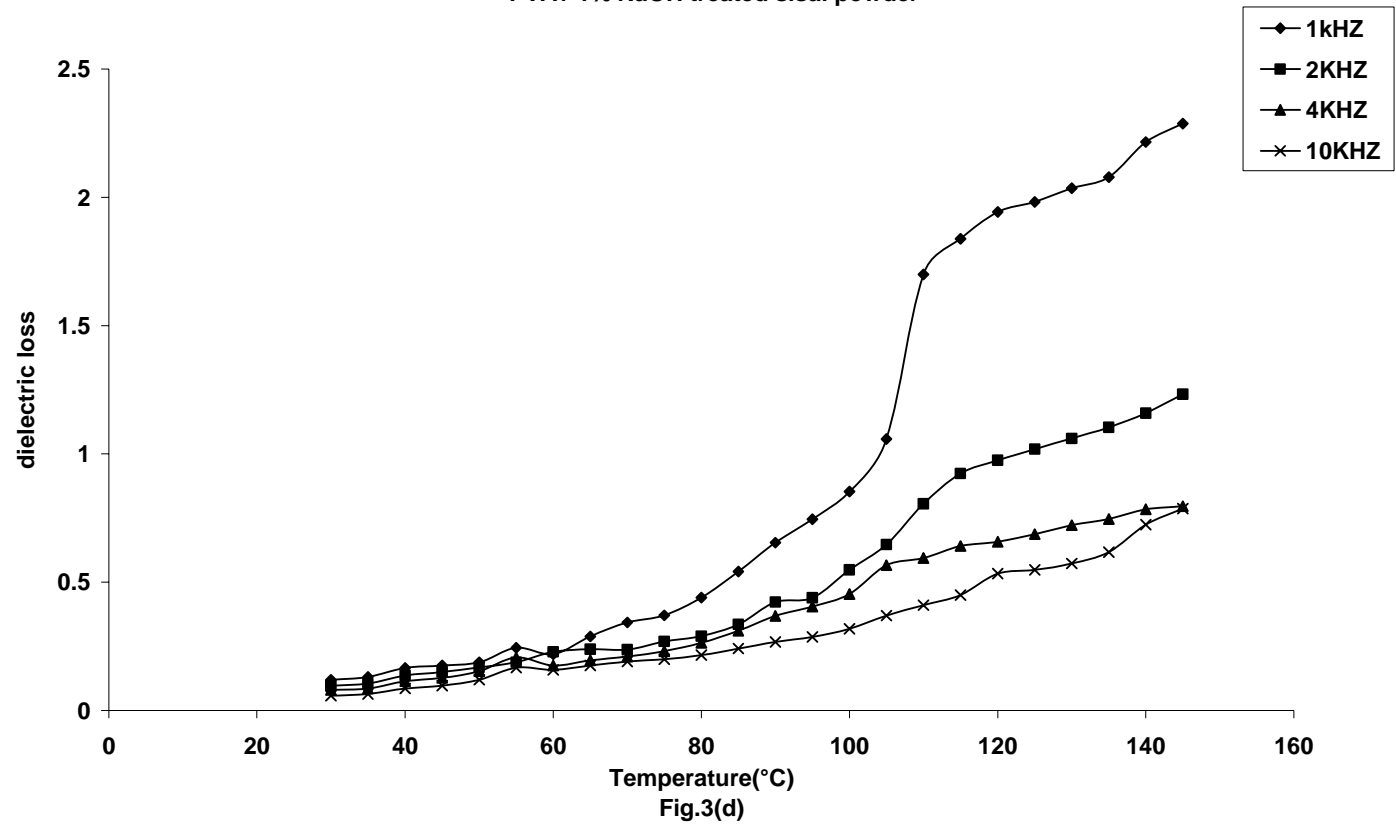

Fig. 3(d) variation of Dielectric Loss with temperature for PVA $+1 \mathrm{wt} \%$

$(5 \% \mathrm{NaOH}$ treated sisal fibre powder) composite film at $1,2,4$ and $10 \mathrm{kHz}$ frequencies.

PVA $+3 \%$ Treated sisal Powder

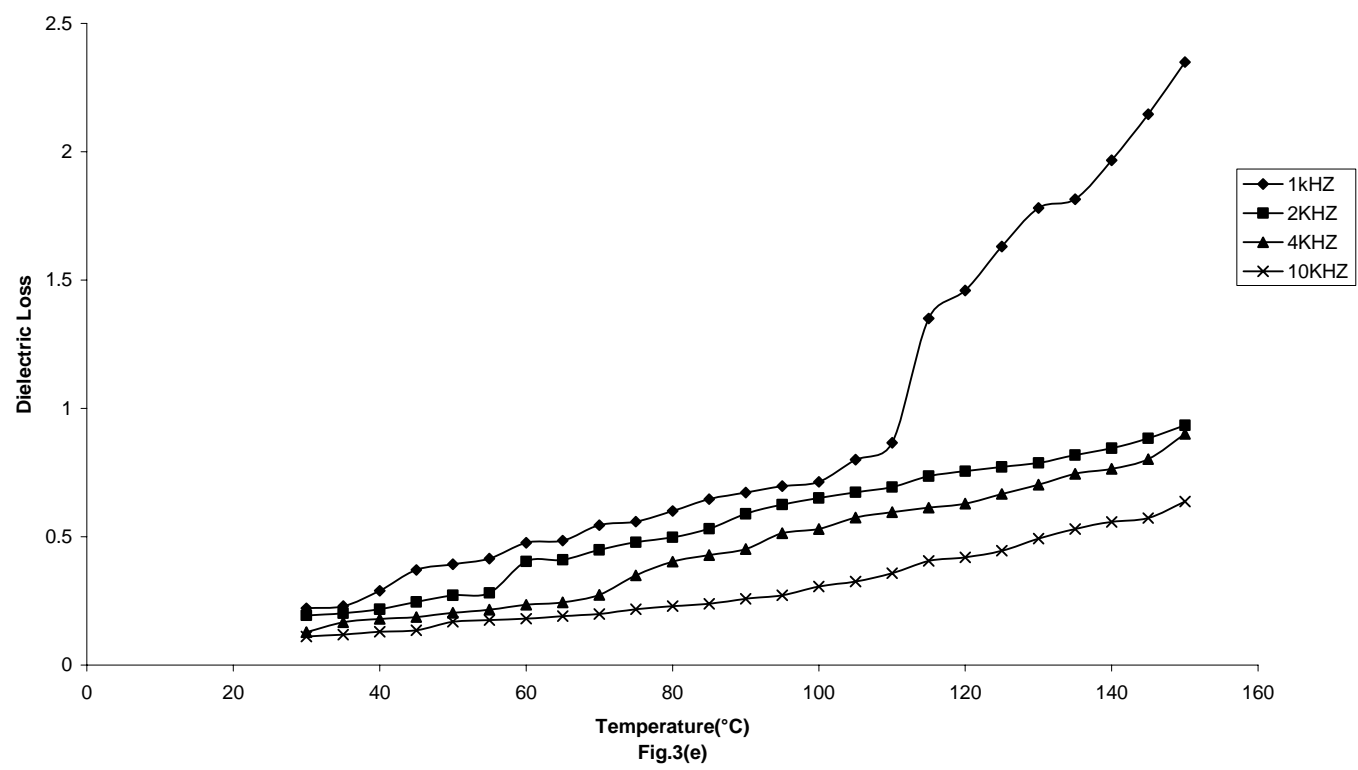

Fig. 3(e) variation of Dielectric Loss with temperature for PVA $+3 \mathrm{wt} \%$ $(5 \% \mathrm{NaOH}$ treated sisal fibre powder) composite film at 1,2, 4 and $10 \mathrm{kHz}$ frequencies. 
PVA+5\% Treated sisal Powder

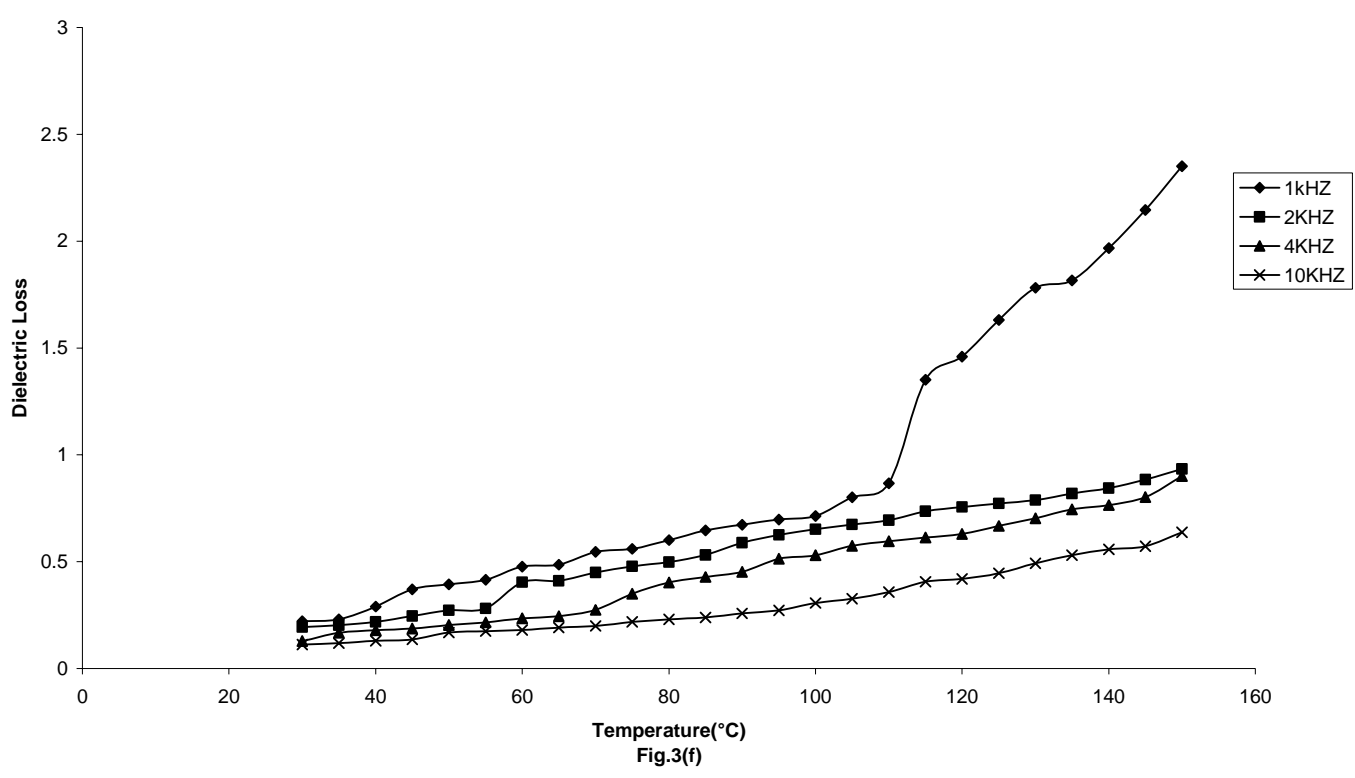

Fig. 3(f) variation of Dielectric Loss with temperature for PVA $+5 \mathrm{wt} \%$ $(5 \% \mathrm{NaOH}$ treated sisal fibre powder) composite film at $1,2,4$ and $10 \mathrm{kHz}$ frequencies.

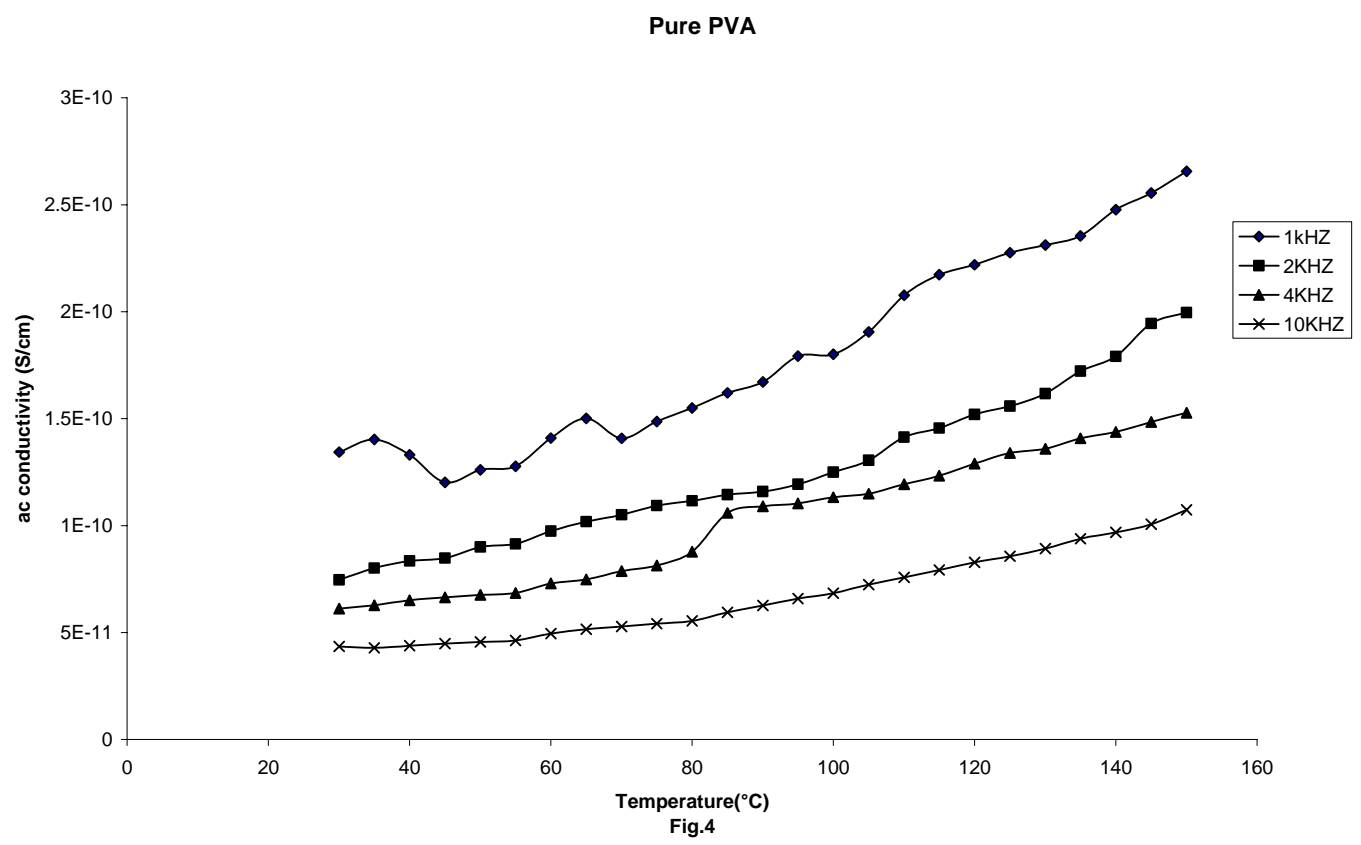

Fig. 4 variation of $\sigma_{\text {a.c. }}$ with temperature for pure PVA composites film at 1, 2, 4 and $10 \mathrm{kHz}$ frequencies. 
PVa+1\% Ut Sisal

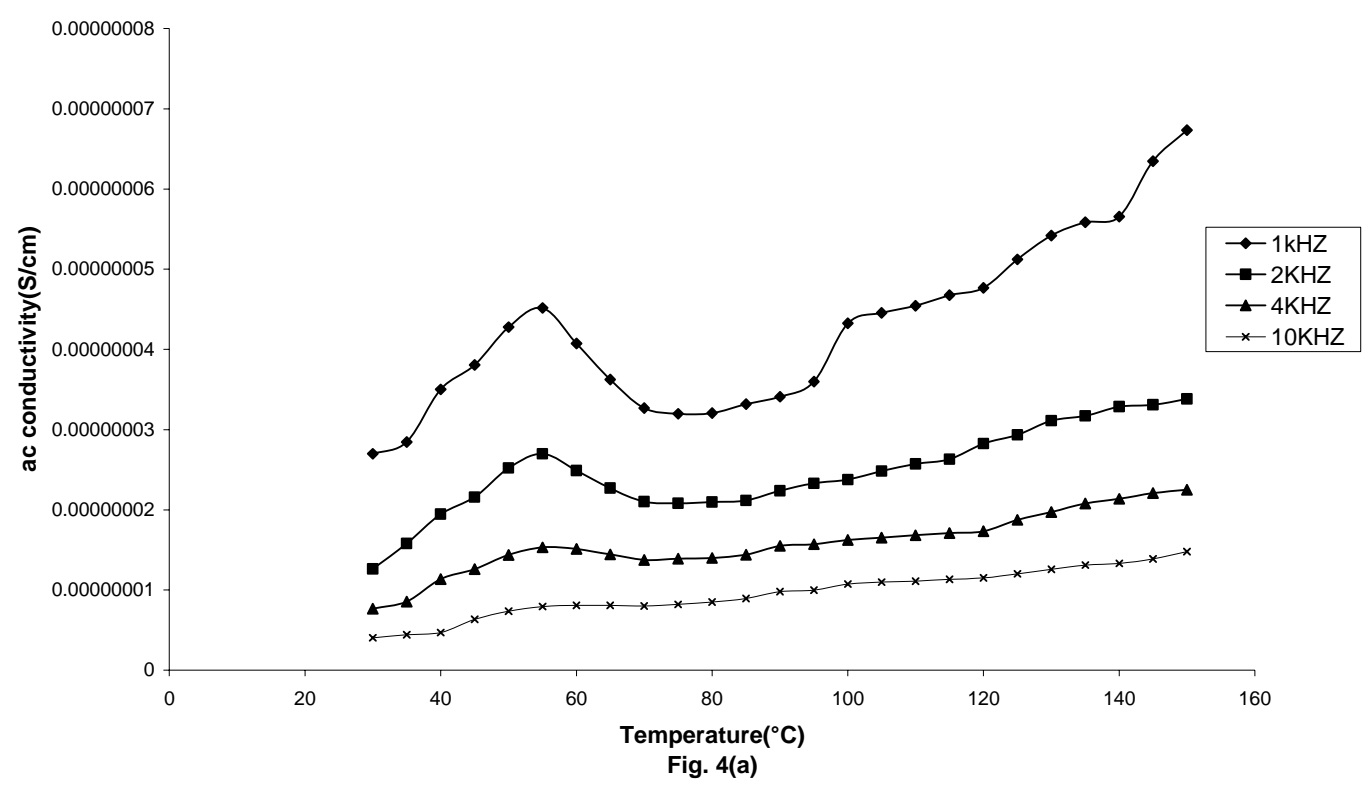

Fig. 4(a) variation of $\sigma_{\text {a.c. }}$ with temperature for $1 \mathrm{wt} \%$

(untreated sisal fibre powder) filled PVA composites film at 1,2, 4 and $10 \mathrm{kHz}$ frequencies.

PVA+3\% Untreated Sisal Fibre powder

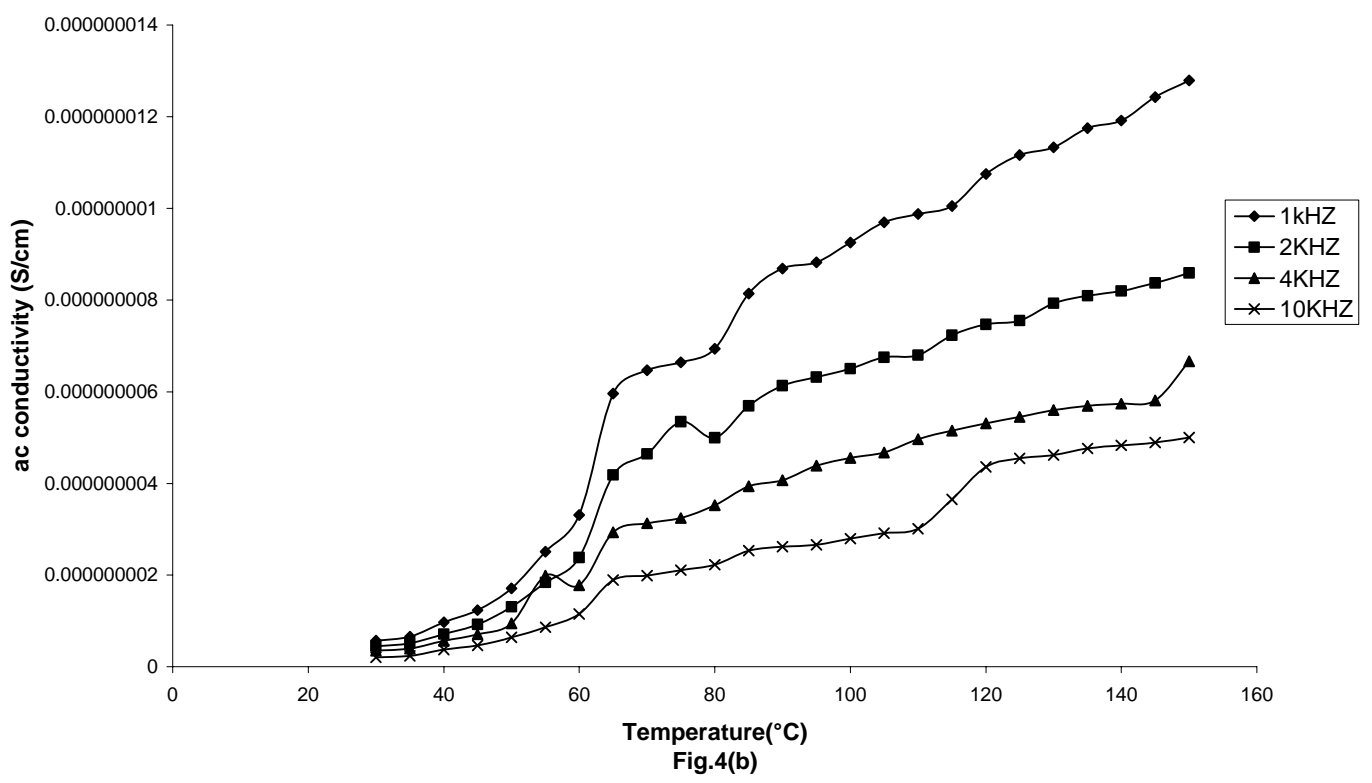

Fig. 4(b) variation of $\sigma_{\text {a.c. }}$ with temperature for $3 \mathrm{wt} \%$

(untreated sisal fibre powder) filled PVA composites film at 1,2, 4 and $10 \mathrm{kHz}$ frequencies. 
PVA+5\% Untreated Sisal fibre powder

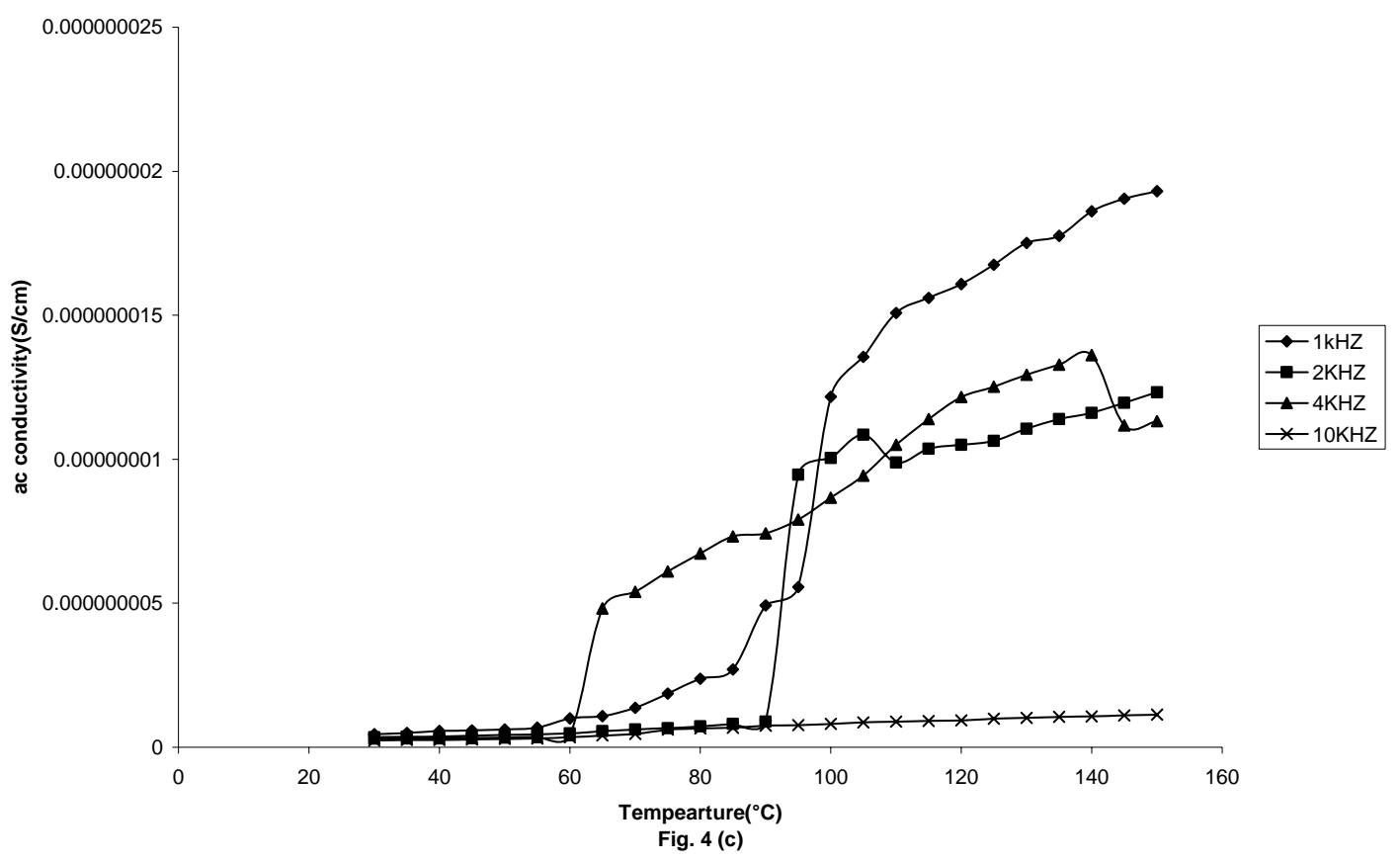

Fig. 4(c) variation of $\sigma_{\text {a.c. }}$ with temperature for $5 \mathrm{wt} \%$

(untreated sisal fibre powder) filled PVA composites film at 1,2, 4 and $10 \mathrm{kHz}$ frequencies.

PVA+ 1wt\%Sisal Fibre

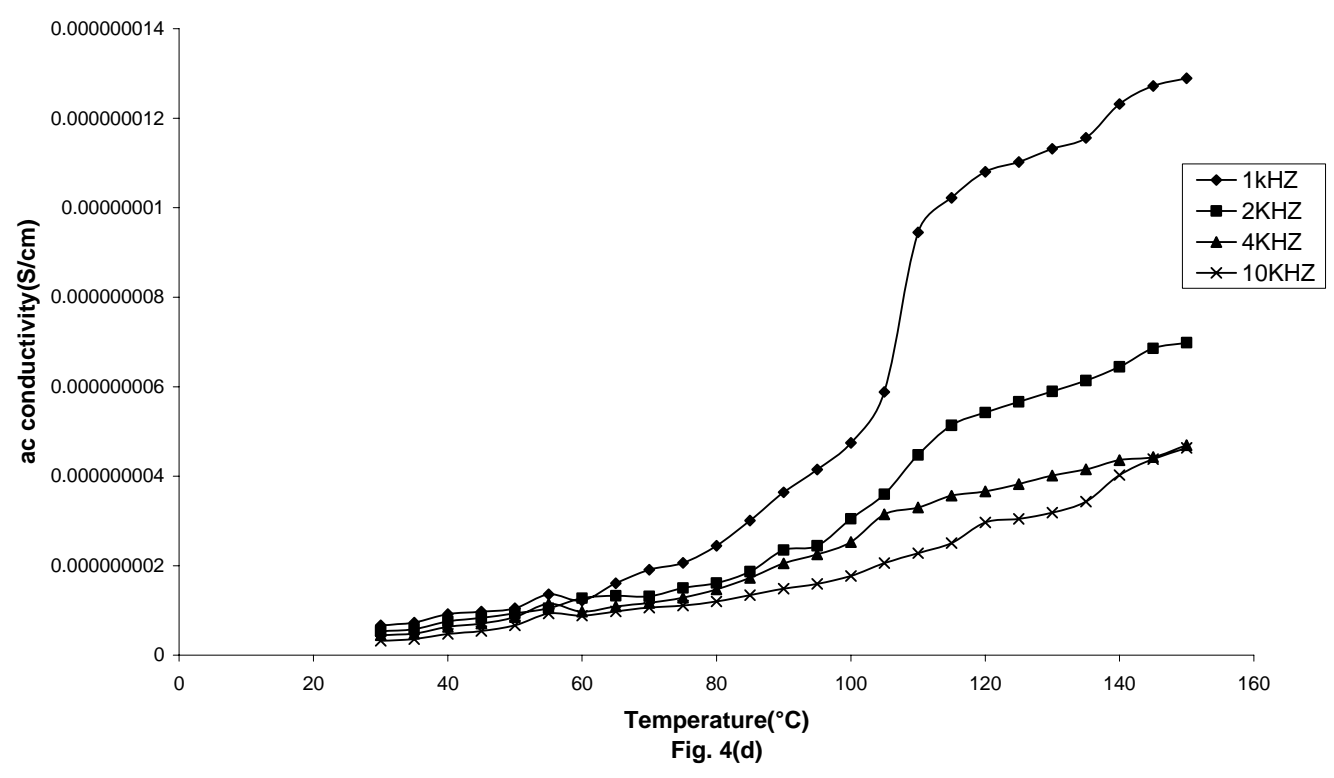

Fig. 4(d) variation of $\sigma_{\text {a.c. }}$ with temperature for PVA $+1 \mathrm{wt} \%$

$(5 \% \mathrm{NaOH}$ treated sisal fibre powder) composite film at $1,2,4$ and $10 \mathrm{kHz}$ frequencies. 
PVA+ 3\% Treated sisal powder

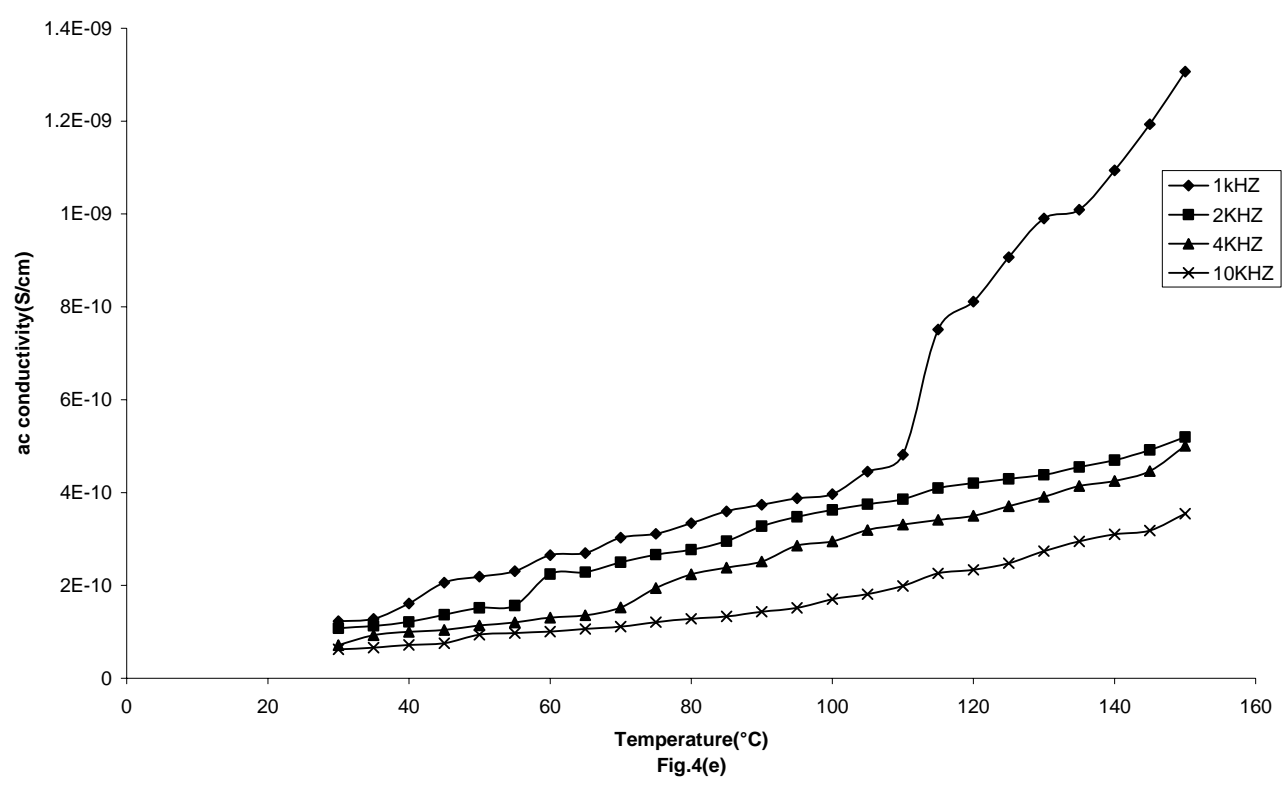

Fig. 4(e) variation of $\sigma_{\text {a.c. }}$ with temperature for $\mathrm{PVA}+3 \mathrm{wt} \%$

$(5 \% \mathrm{NaOH}$ treated sisal fibre powder) composite film at $1,2,4$ and $10 \mathrm{kHz}$ frequencies.

PVA+5\% Treated Sisal Fibre Powder

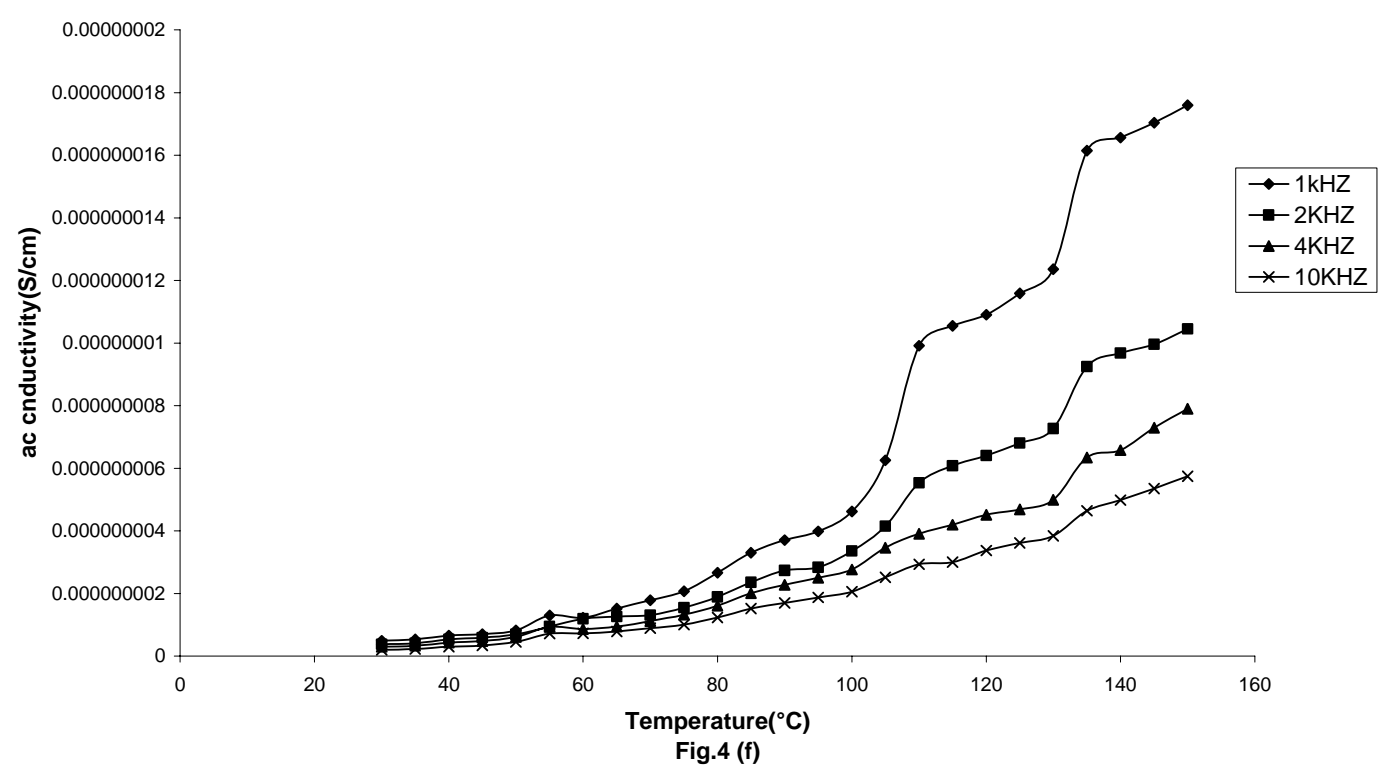

Fig. 4(f) variation of $\sigma_{\text {a.c. }}$ with temperature for PVA $+5 \mathrm{wt} \%(5 \% \mathrm{NaOH}$ treated sisal fibre powder $)$ composite film at 1,2, 4 and $10 \mathrm{kHz}$ frequencies.

\section{Conclusions}

The following are the conclusions that could be made from the study:

- Dielectric behavior depended on the concentration of filler as well as temperature and frequency.

- Dissipation factor $(\tan \delta)$ plots for composites exhibit two relaxation peaks. 
- The dielectric properties, such as dielectric constant, dielectric loss of sisal fiber reinforced PVA composites have been studied as a function of frequency and temperature and chemical modification of fibers. The dielectric constant values have been found to be higher for fiber filled composites than pure PVA. This has been attributed to the polarization exerted by the incorporation of fibers into the PVA. Dielectric constant values were observed to be decreased with increase in frequency due to the decreased interfacial and orientation polarization at higher frequencies. Dielectric loss increases almost linearly with increasing filler loading. Chemical modification of fibers resulted in decrease of dielectric constant values.

These newly developed composites can be useful in insulator applications, and packaging industries.

\section{Acknowledgement}

The financial support to Dr. Archana Nigrawal by the DST (FAST TRACK SCHEME-SR/FTP/ETA-84) project is gratefully acknowledged.

\section{References}

Andrej K.B., Marta L., Abdullah A. and Janusz M. 2009. Biological and electrical resistance of acetylated flax fiber reinforced polypropylene composites, Bioresources, Vol.4, No.1. pp. 111-126.

Chand N., Nigrawal A. and Jain D. 2008. Dielectric behavior of maleic anhydride grafted polypropylene (MAgPP) modified sisal fiber reinforced pp composites, Journal of Natural Fibers, Vol. 5, No.3, pp. 270-288.

Idicula M., Boudenne A., Umadevi L., Ibos L., Candau Y., Thomas S., 2006. Thermophysical properties of natural fibre reinforced polyester composites,..Composite Science Technology, Vol. 66, pp.2719-2725.

Jayamol G., Bhagwan S.S., and Thomas S., 1997. Electrical properties of pineapple fiber reinforced polyethylene composite, Journal of Polymer Engineering, Vol.17, No. 5, pp. 383-404.

Kalaprasad G., Pradeep P., Mathew G., Pavithran C., Thomas S. 2000. Thermal conductivity and thermal diffusivity analyses of low-density polyethylene composites reinforced with sisal, glass and intimately mixed sisal/glass fibres, Composite Science and Technology, Vol.60, pp. 2967-2977.

Mahmoud W. E., Hafez M., El-Aal N. A., El-Tantawy F., 2008. The effect of nanoscale vanadium pentoxide on the electrical and mechanical properties of poly (vinyl alcohol), Polymer International, Vol. 57, No. 1, pp. 35-38.

Maya J., Varughese K.T. and Sabu T. 2006., Dielectric characteristics of sisal-oil palm hybrid biofiber reinforced natural rubber biocomposites, Journal of Material Science, Vol.41, No.17, pp. 5538-5547.

Miah M. J., Ahmed F., Hossain A., Khan A. H. and Khan A.M., 2005. Study on mechanical and dielectric properties of jute fiber reinforced low-density polyethylene (LDPE) composites. Polymer Plastic Technology and Engineering, Vol. 44, pp. 14431456.

Nayak S.K., Mohanty S. 2010. Sisal glass fiber reinforced PP hybrid composites: effect of MAPP on the dynamic mechanical and thermal properties. Journal of Reinforced Plastic Composites; Vol.29, No.10, pp..1551-1568.

Nigrawal A., Prajapati S.C., Sharma R. and Chand N. 2011. Influence of nano alumina addition on strength, structure and thermal behavior of chemically treated sisal powder filled polyvinyl alcohol (PVA) biocomposites. Composite Interfaces, Vol.18 pp. 725-736.

Ramakrishna M., Kumar V., and Yuvraj N. S., 2009. Recent development in natural fiber reinforced polypropylene composites, Journal of Reinforced Plastics and Composites, Vol.28: pp. 1169-1189.

Samal S.K., Mohanty S., Nayak S.K. 2009. Polypropylene-bamboo/glass fiber hybrid composites: fabrication and analysis of mechanical, morphological, thermal, and dynamic mechanical behaviour. Journal of Reinforced Plastic Composites; Vol.28, No. 22, pp. 2729-2747.

Scarponi C. and Pizzinelli C.S., 2009. Interface and mechanical properties of natural fibres reinforced composites: a review, International Journal of Materials and Product Technology, Vol.36, 4, pp.278-303.

Yang G. C., Zeng H. M.,. Li J. J, Jian N. B., Zhang W. B., 1996. Relation of modification of tensile properties of sisal fiber. Acta Science National University Sunyatseni, Vol. 35, pp. 53-57.

\section{Biographical notes}

Archana Nigrawal is with Advanced Materials and Processes Research Institute, Bhopal (CSIR) (formerly RRL Bhopal), Habibganj Naka,Bhopal -462064, India. 
Navin Chand works with is with Advanced Materials and Processes Research Institute, Bhopal (CSIR) (formerly RRL Bhopal), Habibganj Naka,Bhopal 462064, India.

Received February 2012

Accepted August 2012

Final acceptance in revised form September 2012 